Review

Subscriber access provided by b-on / UNIVERSIDADE DO MINHO

\section{Current Concepts and Challenges in Osteochondral Tissue Engineering and Regenerative Medicine \\ Leping Yan, Joaquim Miguel Oliveira, Ana Leite Oliveira, and Rui L. Reis}

ACS Biomater. Sci. Eng., Just Accepted Manuscript • DOI: 10.1021/ab500038y • Publication Date (Web): 20 Feb 2015

Downloaded from http://pubs.acs.org on February 25, 2015

\section{Just Accepted}

"Just Accepted" manuscripts have been peer-reviewed and accepted for publication. They are posted online prior to technical editing, formatting for publication and author proofing. The American Chemical Society provides "Just Accepted" as a free service to the research community to expedite the dissemination of scientific material as soon as possible after acceptance. "Just Accepted" manuscripts appear in full in PDF format accompanied by an HTML abstract. "Just Accepted" manuscripts have been fully peer reviewed, but should not be considered the official version of record. They are accessible to all readers and citable by the Digital Object Identifier (DOI®). "Just Accepted" is an optional service offered to authors. Therefore, the "Just Accepted" Web site may not include all articles that will be published in the journal. After a manuscript is technically edited and formatted, it will be removed from the "Just Accepted" Web site and published as an ASAP article. Note that technical editing may introduce minor changes to the manuscript text and/or graphics which could affect content, and all legal disclaimers and ethical guidelines that apply to the journal pertain. ACS cannot be held responsible for errors or consequences arising from the use of information contained in these "Just Accepted" manuscripts. 


\title{
Current Concepts and Challenges in Osteochondral Tissue Engineering and Regenerative Medicine
}

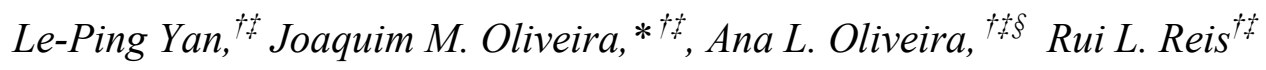 \\ †3B's Research Group-Biomaterials, Biodegradables and Biomimetics, University of Minho, \\ Headquarters of the European Institute of Excellence on Tissue Engineering and Regenerative \\ Medicine, AvePark, S. Cláudio de Barco, 4806-909 Taipas, Guimarães, Portugal. \\ ${ }^{\ddagger}$ ICVS/3B’s-PT Government Associate Laboratory, Braga/Guimarães, Portugal. \\ ${ }^{\S} \mathrm{CBQF}-$ Center for Biotechnology and Fine Chemistry, School of Biotechnology, Portuguese \\ Catholic University, Porto, 4200 - 072, Portugal.
}

*Corresponding Author: Dr. Joaquim M. Oliveira (E-mail: miguel.oliveira@dep.uminho.pt) 


\section{Abstract}

In the last few years, great progress has been made to validate tissue engineering strategies in preclinical studies and clinical trials on the regeneration of osteochondral defects. In the preclinical studies, one of the dominant strategies comprises the development of biomimetic/bioactive scaffolds, which are used alone or incorporated with growth factors and/or stem cells. Many new trends are emerging for modulation of stem cell fate towards osteogenic and chondrogenic differentiations, but bone/cartilage interface regeneration and physical stimulus have been showing great promise. Besides the matrix-associated autologous chondrocyte implantation (MACI) procedure, the matrix-associated stem cells implantation (MASI) and layered scaffolds in acellular or cellular strategy are also applied in clinic. This review outlines the progresses at preclinical and clinical levels, and identifies the new challenges in osteochondral tissue engineering. Future perspectives are provided, e.g., the applications of extracellular matrix-like biomaterials, computer-aided design/manufacture of osteochondral implant and reprogrammed cells for osteochondral regeneration.

Keywords: Osteochondral tissue engineering; Layered scaffold; Biomimetic; Interface engineering; Clinical trial, Pluripotent stem cells 


\section{Introduction}

Articular cartilage is a connective tissue that acts as a shock absorber and facilitates joint's motion in low friction. ${ }^{1}$ Many reasons can lead to cartilage lesions, such as traumatic events, chronic repetitive microtrauma, and aging. Cartilage lesions are normally irreparable due to the typical avascular nature of cartilage and consequent lack of supplementation of potentially reparative cells/bioactive factors. ${ }^{2}$ As the cartilage lesion progresses, it extends to the underlying subchondral bone and osteochondral defect (OCD) appears. Other diseases originating from the subchondral bone and subsequently reaching the cartilage layer can also induce OCD, such as osteochondritis dissecans and osteonecrosis. ${ }^{3}$ Osteochondral (OC) fracture, which is a common injury in children and adolescents, represents one cause for OCD. Besides the OCD in the knee, nowadays an increasing amount of attention is being given to OC lesions of the talus (OLTs) because they primarily affect young athletic population and often lead to long-term disability. ${ }^{4,5}$ Similarly, OC fractures of the patella represent a major complication following patellar instability or dislocation. ${ }^{6}$ OCD often causes the formation of fibrocartilage which only provides poor protection to the subchondral bone. Subsequent degradation of the repaired and adjacent tissues is often observed. ${ }^{2}$ Furthermore, OCD is associated with severe pain, impaired joint mobility and low quality of life. It also generates huge amount of health care costs every year. In the United States alone, the annual cost for the treatment of OCD is about $\$ 95$ billion. $^{7}$

There has been increased evidence that without the support from the subchondral bone, any treatment of the cartilage layer is likely to fail. ${ }^{3,8}$ Thus, the cartilage and subchondral bone should be taken into account as one unit during OC regeneration, instead of being considered separately. Actually, the cartilage layer and subchondral bone are tightly connected. No matter what type of the lesion it is, either from the cartilage or from the subchondral bone, the 
connected and surrounding tissues will always be affected, contributing negatively to the mechanical homeostasis of the whole joint. Therefore, the main goal for OC regeneration is to restore its biomechanical properties, besides the regeneration of the defect.

Currently, there are several methods used in the clinical setting for treating OCD. Arthroscopic debridement is used to trim the loose cartilage in small defects and only for the relief of pain for the patients. For defects between 1 and $2.5 \mathrm{~cm}^{2}$, microfracture is commonly selected. ${ }^{9}$ For this method, microfractures are created from the cartilage defect until reaching the subchondral bone. The access of mesenchymal stem/stromal cells (MSCs) and growth factors from bone marrow and blood facilitates the formation of fibrocartilage on the defect. Patients who received this treatment often need revision interventions after some time, i.e. some degradation of the tissue was reported around 18 months post-operatively. Arthroscopic debridement and microfracture are palliative methods for OCD treatment. OC autograft transplantation (mosaicplasty, OATS) constitutes another option if the defect size is between 1 and $4.0 \mathrm{~cm}^{2} \cdot{ }^{10,11}$ However, this method would create new OCD in the body and has limited availability of the donor tissues. For lesions of size higher than $2.5 \mathrm{~cm}^{2}$, autologous chondrocyte implantation (ACI) technology has been widely used. This method presents an advantage of possibly achieving regeneration with hyaline cartilage. However it requires two-step surgeries and may induce complications of chondrocyte apoptosis and necrosis, or hypertrophy of the cells. $^{12,13}$

Recently, tissue engineering strategy emerged as a promising alternative to regenerate OCD. ${ }^{14}$ Tissue engineering is a multi-disciplinary approach, involving the advances in material science, chemical engineering, biology, and medicine. ${ }^{15}$ Probably the currently most appealing clinical application of tissue engineering for $\mathrm{OC}$ regeneration is the matrix-associated autologous 
chondrocyte implantation (MACI) technology. ${ }^{16}$ In order to achieve ideal OC regeneration, numerous efforts have been made on scaffold/hydrogel development, stem cells differentiation, growth factors incorporation, and animal models. ${ }^{14,17-19}$ Furthermore, a few studies have been extended to clinical trials. ${ }^{20-22}$ Many important and interesting findings were made, and some new technologies and subjects have emerged during the last few years. ${ }^{23-25}$

In this review, the most important breakthroughs in OC tissue engineering in the past few years were overviewed. Moreover, this review also intends to add new insights regarding the current research status and challenges in OCD preclinical studies and clinical trials using tissue engineering strategies. In addition, the new trends and future directions in OC tissue engineering are briefly discussed.

\section{Tissue Engineering Strategies in OC Regeneration}

\section{In Vitro Studies on OC Tissue Engineering}

Biomaterials, bioactive agents, and cells are the three key factors for tissue engineering strategy. A lot of biomaterials have been explored for OC regeneration in vitro. These materials include synthetic or natural polymers, bioceramics, and composites of these materials. ${ }^{26-29}$ It is necessary to study the biological performances of these materials by in vitro cell culture after processing them into different formats, such as porous scaffolds and hydrogels of non-layered or layered structure. $^{30-32}$

\section{Layered scaffolds}

As a stratified tissue, OC tissue is composed of collagen (Col) II and glycosaminoglycan (GAG) in the hydrogel-like cartilage layer, and hydroxyapatite (HA) and Col I in the highly porous 
subchondral bone layer. ${ }^{26}$ Inspired by the structure and components of OC tissue, biomimetic strategies have been introduced to produce scaffolds displaying similar structural or chemical properties to OC tissue. $^{26}$ For example, layered constructs which presented similar microenvironments to the corresponding layers of OC tissue were studied intensively. ${ }^{26,33,34}$

Oliveira et al. developed a well-integrated bilayered porous HA and chitosan scaffold. ${ }^{26}$ Osteogenic differentiation (14 days) and chondrogenic differentiation (28 days) of goat bone marrow mesenchymal stromal cells (BMSCs) were performed on the separated HA and chitosan layers, respectively. Results showed that the alkaline phosphatase (ALP) content increased in the HA scaffolds after 2 weeks osteogenic differentiation. Osteopontin and Col I were also observed in the HA scaffolds via the immunofluorescence labeling. The chitosan scaffolds presented enhanced GAG content from day 7 to 21 . In another study, multilayered porous scaffolds were developed which consisted of gradient HA content between the collagen and the collagen/HA layers. ${ }^{34}$ Human BMSCs (hBMSCs) were seeded onto the separated collagen and collagen/HA layers, and then both the chondrogenic differentiation (28 days) and osteogenic differentiation (14 days) of the cells were performed for these two groups of scaffolds, respectively. The chondrogenic differentiation results showed that the collagen layer induced superior chondrogenic genes (Sox-9, Col 2a1 and aggrecan) expressions compared with the collagen/HA layer at day 21. Furthermore, the GAG contents in the collagen layer were higher than the ones in the collagen/HA layer at day 14 and 28. In case of osteogenic differentiation, the collagen/HA layer showed superior ALP content at day 5, 10 and 13, and displayed higher amounts of Runx2, ALP, Col 1a1, osteopontin and osteocalcin genes at day 14, compared with the ones of the collagen layer. 
Mimicking the micromechanical environment of OC tissue, hydrogels and porous scaffolds were combined to form bilayered scaffolds. ${ }^{31,32,35}$ In one study from Hung et al., agarose with encapsulated bovine chondrocytes was penetrated into the devitalized bovine tibia trabecular bone to generate the cylindrical bilayered OC construct. ${ }^{35}$ The constructs were cultured in Dulbecco's modified Eagle's medium (DMEM) supplemented with 10\% fetal bovine serum (FBS) and $50 \mu \mathrm{g} / \mathrm{ml}$ ascorbic acid for 42 days. They also produced chondrocytes-seeded agarose of anatomical patellar shape and then integrated the agarose constructs with trabecular bone of corresponding anatomical shape to form the osteochondral constructs which were subsequently cultured in the above mentioned medium for two weeks. Results showed that the chondrocytes were viable in these two experiments and the agarose still firmly integrated with the bony substrate during the culture time periods. These constructs presented positive Col II staining, as well as enhanced GAG contents and mechanical properties. In a following study, hBMSCs were pre-differentiated into chondrocytes and osteoblasts for 1 week firstly and then these cells were incorporated into the agarose (chondrocytes) layer and decellularized trabecular bone layer (osteoblasts) of the bilayered scaffolds, respectively. ${ }^{32}$ Undifferentiated hBMSCs were used as control and seeded into the same bilayered scaffolds. The constructs were placed into perfusion bioreactors and cultured in either chondrogenic medium or cocktail medium containing chondrogenic and osteogenic supplements for 5 weeks. The control constructs were kept under static or bioreactor culture in the chondrogenic or cocktail medium for 5 weeks. It was found that pre-differentiated BMSCs only favored bone formation, while the perfusion condition and cocktail medium inhibited chondrogenesis of BMSCs. The perfusion bioreactor was helpful to improve the integration of bone-cartilage interface. In order to further efficiently guide the cells toward OC differentiate, new culture technologies should be explored. 


\section{Biological cues}

It has been reported that some growth factors or drugs are efficient in modulation of cellular differentiation. For example, transforming growth factor- $\beta 1$ (TGF- $\beta 1$ ) or transforming growth factor- $\beta 3$ (TGF- $\beta 3$ ) can induce chondrogenesis of the MSCs, and bone morphogenetic proteins (BMP) are suitable for guiding the osteogenesis of MSCs. ${ }^{36,37}$ These bioactive reagents have been introduced into the scaffolds to improve the cellular differentiation toward OC regeneration.

Guo et al. developed bilayered poly(ethylene glycol) fumarate hydrogels (OPF) which contained gelatin microparticles loaded with TGF- $\beta 1$ in the chondral layer. ${ }^{28}$ The chondral layer encapsulated undifferentiated rabbit BMSCs, while the bony layer consisted of rabbit BMSCs or osteogenically differentiated BMSCs (6 days). Bilayered hydrogels only with BMSCs and unloaded microparticles, or bilayered hydrogels with BMSCs in the chondral layer and osteogenically differentiated BMSCs in the bony layer and blank microparticles, were used as controls. All the constructs were cultured in chondrogenic medium supplemented with $\beta$-glycerol phosphate $(\beta-\mathrm{GP})$ for 28 days. The results showed that chondrogenesis was observed in the chondral layer, especially in the presence of TGF- $\beta 1$. In the bony layer, osteoblastic phenotype of the cells was maintained. Calcium deposition was limited, but this layer promoted chondrogenic differentiation of BMSCs in the chondral layer. The optimal results were displayed in the group with growth factor loaded microparticles and osteogenic differentiated BMSCs. In another similar study, gelatin microparticles loaded with rabbit BMSCs and TGF- $\beta 3$ were incorporated into the chondral layer of the bilayered OPF hydrogels. ${ }^{36}$ BMSCs undergone varied osteogenic differentiation time periods $(0,3,6,12$ days $)$ were encapsulated into the bony layer of the bilayered OPF hydrogels. Bilayered hydrogels including chondral layer without growth 
factor but bony layer with BMSCs of varied osteogenic differentiation time were used as controls. All the bilayered constructs were cultured in chondrogenic medium plus $\beta$-GP for 28 days. In the chondral layer, TGF- $\beta 3$ significantly promoted chondrogenic differentiation of BMSCs. Osteogenically differentiated cells along with TGF- $\beta 3$ improved the chondrogenic gene expression of the BMSCs. In the bony part, cells maintained ALP activity during coculture, while mineralization was delayed in the presence of TGF- $\beta 3$.

Spatiotemporal modulation of the delivery of growth factors in the scaffolds is essential for guiding the BMSCs differentiation during OC regeneration. Bone morphogenetic protein-2 (BMP-2) and TGF- $\beta 1$ loaded poly(lactic-co-glycolic acid) (PLGA) microspheres were used to fabricate microsphere based PLGA scaffolds with opposite gradient of the two growth factors by Dormer et al. ${ }^{37}$ Human BMSCs (hBMSCs) or human umbilical cord mesenchymal stromal cells (UCMSCs) were seeded onto these scaffolds. The constructs were cultured in defined DMEM for the first three days and then in defined medium supplemented with $\beta$-GP and dexamethasone for 6 weeks. Blank scaffolds, single phase scaffolds (with BMP-2 or TGF- $\beta 1$ ), or biphasic scaffolds (with BMP-2 or TGF- $\beta 1$ in each layer) were used as controls. The results demonstrated that the hBMSCs responded well to the gradient design through their gene expressions (Col I, Sox9 and Runx2), but there were no significant differences compared with UCMSCs in terms of the biochemical performances (DNA, GAG, ALP and hydroxyproline contents). The gradient scaffolds produced regionalized extracellular matrix (ECM), and were superior as compared with the blank control scaffolds in cellular number, GAG production, collagen content, and ALP activity. In another study, Wang et al. incorporated recombinant human BMP (rhBMP) and recombinant human insulin-like growth factor-1 (rhIGF-1) in PLGA or silk microparticles. ${ }^{38}$ Next, these growth factors were distributed in cylindrical alginate gels or 
aqueous derived salt-leached silk scaffolds with a gradient concentration of one growth factor or reverse gradient concentrations of these two growth factors. The influences of the gradient concentration of the growth factors on hBMSCs were investigated by seeding the cells onto the scaffolds or encapsulating the cells in the gels. The constructs were cultured in medium containing osteogenic and chondrogenic components for 5 weeks. In the case of alginate gels, it was found that silk microspheres were more efficient in rhBMP-2 delivery and less efficient in delivering rhIGF-1 compared with PLGA microspheres. The growth factor gradients induced non-gradient trends in hMSCs OC differentiation, due to shallow gradients. Regarding the silk scaffold group, the cells presented osteogenic and chondrogenic differentiations along the gradient concentration of rhBMP-2 or reverse gradient of rhBMP-2/rhIGF-1, but not in the rhIGF-1 gradient system.

The above mentioned studies provide useful insights for OC regeneration, as well as for creation of complex tissues. In the future, development of growth factors of low cost, such as from human platelet releasate, would be of great interest. ${ }^{39}$

\section{Stem cells}

Besides primary cells (osteoblasts and chondrocytes), increasing attention has been shifted to stem cells for OC regeneration, such as BMSCs, adipose tissue-derived stem cells (ADSCs), UCMSCs and amniotic fluid-derived stem cells (AFSCs). ${ }^{26,40-42}$

In the studies from Guo et al., the osteogenically pre-differentiated BMSCs were encapsulated in the OPF hydrogels and the cells maintained their osteoblastic phenotype and ALP activity, even though the calcium deposition was limited or delayed. ${ }^{28,}{ }^{36}$ Dormer et al. compared the human BMSCs and UCMSCs by seeding them in growth factor loaded PLGA scaffolds and 
found that there were no significant differences between these cells regarding biochemical performances. ${ }^{37}$ ADSCs were seeded onto the electrospun poly( $\varepsilon$-caprolactone) (PCL) scaffolds with opposite gradient concentrations of insulin and $\beta-\mathrm{GP}$, and the constructs were cultured for 8 weeks. ${ }^{40}$ The results showed that chondrogenic differentiation of the cells increased in the insulin-rich region and mineralization matrix enhanced at $\beta$-GP rich domain. In another study, AFSCs were encapsulated into agarose gels (chondral layer) or seeded onto the starch-PCL (SPCL) scaffolds (bony layer) and subsequently the constructs underwent chondrogenic or osteogenic differentiations, respectively. ${ }^{42}$ After chondrogenic and osteogenic differentiations occurring, the agarose and SPCL constructs were integrated by agarose solution and the formed bilayered constructs were cultured under OC co-culture medium or OC co-culture medium plus insulin-like growth factor-1 (IGF-1) for 2 weeks. Basic amniotic fluid cell medium was used as control. Results displayed that osteogenically pre-differentiated AFSCs did not need further OC medium to maintain their phenotype, while the chondrogenically pre-differentiated ones still required OC medium (without IGF-1) to maintain their phenotypes.

\section{Interface regeneration}

During OC regeneration, most of the attention has been given to the generation of the integrated cartilage layer and the subchondral layer. Only recently, there is increased awareness that the regeneration of the interface between chondral and subchondral bone also plays an important role in OC tissue engineering. ${ }^{23}$ The $\mathrm{OC}$ interface is a calcified cartilage layer located between the hyaline cartilage and the subchondral bone. ${ }^{23,35,43}$ The hypertrophic chondrocytes and extracellular matrix rich in Col I, II, and X, are the unique properties of this layer. The OC 
interface acts as a barrier minimizing the diffusions of fluids between cartilage layer and subchondral layer, and therefore prevents the invasion of vessels from bone.

Bioactive inorganic biomaterials have been used to direct the differentiation of chondrocytes toward the formation of calcified cartilage. In the study from Jiang et al., agarose gel with encapsulated bovine chondrocytes was firstly integrated with PLGA/bioactive glass microsphere scaffold and then bovine osteoblasts were subsequently seeded onto the PLGA/bioactive glass part. $^{44}$ These multi-phased OC constructs contained a hybrid gel/microsphere interface region between the gel (chondral) and scaffold (bony) layers. The constructs were cultured in DMEM plus ascorbic acid for 20 days. Constructs without bioactive glass were used as control. It was found that the co-culture of chondrocytes and osteoblasts resulted in three distinct yet continuous regions: cartilage, calcified cartilage and bone-like matrices. The PLGA/bioactive glass phase facilitated the formation of calcified interface and promoted chondrocyte mineralization potential around the interface region. Khanarian et al. incorporated bovine deep zone chondrocytes into alginate gels with $1.5 \mathrm{wt} / \mathrm{v} \%$ HA particles $(20 \mu \mathrm{m}) .{ }^{45}$ The constructs were cultured for 4 weeks in DMEM supplemented with ITS Premix, proline and ascorbic acid. Constructs without HA were used as control. The results showed that the HA phase enhanced the formation of GAG and Col II, and also increased mechanical properties as compared with the control. Presence of HA promoted hypertrophy of the chondrocyte, as well as Col X deposition in the constructs. In another study from the same group, the authors encapsulated bovine deep zone chondrocytes and triiodothyronine (T3)-induced hypertrophic deep zone chondrocytes in agarose/HA hybrid gels to mimic the calcified cartilage formation. They studied the different influences of nano-sized and micro-sized HA particles on the hypertrophy of chondrocytes. ${ }^{43}$ The constructs were cultured for 14 days in DMEM supplemented with ITS Premix, proline and ascorbic acid. 
A
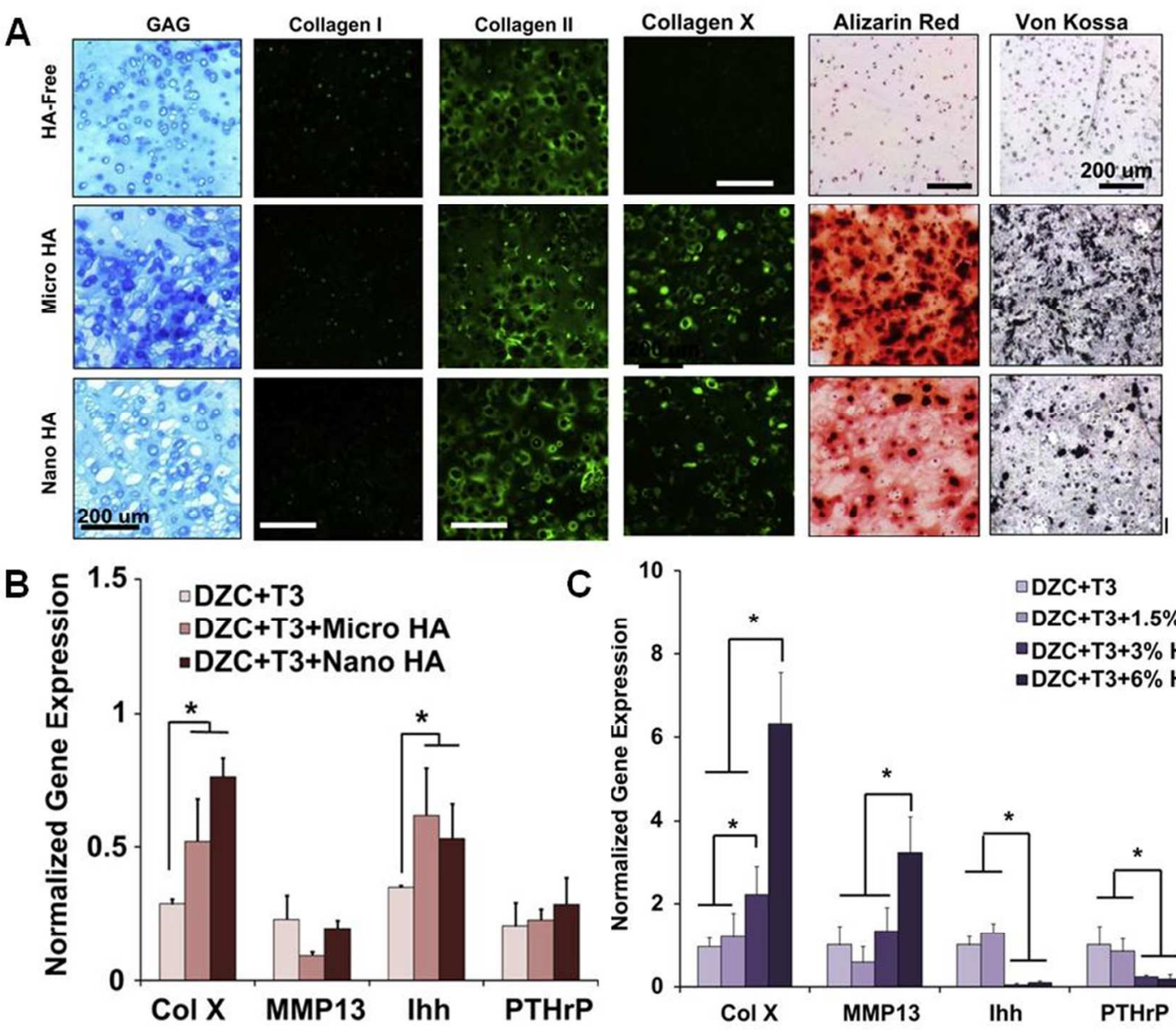

$\square \mathrm{DZC}+\mathrm{T} 3$

$\square \mathrm{DZC}+\mathrm{T} 3+1.5 \% \mathrm{HA}$

-DZC+T3+3\% HA

$=\mathrm{DZC}+\mathrm{T} 3+6 \% \mathrm{HA}$

Figure 1. The influence of HA on hypertrophic chondrocytes after culturing in agarose/HA gels for 14 days. (A) Effect of HA presence (1.5 w/v\% HA) and size (micro and nano-sized) on the biosynthesis and mineralization. Alcian Blue stain (GAG) revealed abundant matrix for the micro-HA group. The immunohistochemistry analysis showed positive Col II and minimal Col I stainings for all the groups, while positive Col X staining was found in the HA containing groups no matter the particle size. Strongly positive mineral staining was seen in the micro-HA group (Alizarin Red and Von Kossa). (B) Effect of HA presence and size on the gene expressions. Both Col X and Ihh expression were upregulated. (C) Effect of HA dose (micro-sized) on the gene 
expressions. A dose-dependent increase in Col X expression was found. Suppression of PTHrP and Ihh expressions were found at the higher HA doses $\left(3 \%\right.$ and $6 \% \mathrm{HA},{ }^{*} p<0.05, \mathrm{n}=3$ normalized to $0 \%$ group). Adapted from Reference (43), with permission from Elsevier.

with non-induced chondrocytes. Higher compressive and shear mechanical properties were observed in the constructs as compared with the acellular ones. Cell hypertrophy was independent of ceramic size, while higher ECM deposition was only displayed in the micro-sized HA group. Allan et al. firstly seeded cow deep zone chondrocytes on top of the calcium polyphosphate (CPP) scaffolds and then cultured the constructs in DMEM supplemented with ascorbic acid. ${ }^{46}$ At day $7, \beta-G P$ was added in the medium and the culture was continued up to 8 weeks. Control culture was without $\beta$-GP. The results showed that cartilage tissue formed and presented two zones, one calcified region adjacent to the CPP scaffold and a hyaline-like zone on the surface. Little or no mineral was observed in the absence of $\beta$-GP. The mineral in the calcified region was HA. The formed cartilage tissue possessed significantly higher stiffness and interfacial shear properties compared with the control.

Besides the primary cells, stem cells have also been investigated for OC interface regeneration. ${ }^{47}$ Cheng et al. encapsulated rabbit BMSCs into collagen microspheres and then cultured the microspheres under chondrogenic or osteogenic conditions for 21 days. ${ }^{23}$ Following, microspheres of each group were packed and glued for continued co-culture for another 21 days. The resulted disc-like chondrogenic and osteogenic aggregates were glued together by a middle layer of collagen gel containing undifferentiated BMSCs. The tri-layered collagen microsphere scaffolds were co-cultured under normal, chondrogenic or osteogenic medium for 14 or 21 days. When co-culture was performed in the chondrogenic medium, the results showed that an intact 
and continuous calcified cartilage zone was formed separating the upper chondrogenic layer and the underlying osteogenic layer. Cells at the interface region presented hypertrophic phenotype. Col II and X, calcium mineral and vertically oriented fibers were presented in the ECM. In the case of osteogenic medium, the upper layer chondrogenic tissue became calcified. In the normal medium, undifferentiated BMSCs were found in the interface, and the pre-differentiated BMSCs were able to maintain their chondrogenic or osteogenic phenotypes. UCMSCs were applied for OC regeneration via a sandwich strategy by Wang et al. ${ }^{41}$ The human UCMSCs were firstly cultured in the PLLA scaffolds and underwent chondrogenic or osteogenic differentiation for 3 weeks. Then, the chondrogenic and osteogenic constructs were sutured together with one layer of highly concentrated and undifferentiated UCMSCs solution in the interface. The constructs were cultured in DMEM low glucose supplemented with dexamethasone and IGF-1 for another 3 weeks. Two chondrogenic constructs, two osteogenic constructs, or one chondrogenic and one osteogenic constructs were sutured (all the three groups without cells in the interface) and used as controls. Results revealed that the chondrogenesis and osteogenesis of UCMSCs before suturing were confirmed by the expression of Col II and Runt-related transcription factor 2 genes, respectively. Increased ECM secretion was observed during the co-culture. The histological and immunohistochemical stainings (GAG, Col I and calcium) results showed that the OC constructs with one layer undifferentiated cells in the interface presented better integration and transition in the constructs as compared with the controls.

Co-culture approach of BMSCs and osteoblasts was introduced for osteochondral interface generation. Chen et al. seeded the rabbit BMSCs in silk scaffolds and placed the constructs in chondrogenic medium for one week. ${ }^{48}$ Meanwhile, rabbit osteoblasts were cultured in the cell culture plate. Afterwards, the three-dimensional (3D) constructs and the two-dimensionally (2D) 
cultured osteoblasts were co-cultured in chondrogenic medium for 3 weeks by contacting them together. Non-co-cultured 3D constructs were used as control. The results demonstrated that moderate downregulation of chondrogenic marker genes (such as Col II and Aggrecan) was observed in comparison with the control group. But the Sox-9 and Col I expressions increased. Only the chondrogenic BMSCs layer in contact with the osteoblasts expressed OC interface markers, such as Col X and MMP-13, which were not observed in the control group.

As these studies bring new insights into OC regeneration, further efforts on controlling the thickness and improving the strength of the interface should be considered.

\section{In Vivo Studies on OC Tissue Engineering}

After the in vitro biological performance examination, the biomaterials should be evaluated by the in vivo studies before going for the clinical trials. Compared with the simplified and optimized culture conditions of the in vitro study, the in vivo study provides more complex environments and thus closely mimics the real scenario of OC tissue. In the literature, it was found that rabbit was a popular animal model for creation of OCD. ${ }^{36}$ Larger animal models were also used, such as pigs. ${ }^{49}$ Subcutaneous implantation models were also used to screen ectopic formation of the tissues. ${ }^{50}$ In OCD model, majority of the studies selected femoral condyles in the knee as the implantation sites. OCD created in patella groove or trochlear groove was also popular model. The in vivo studies offer important information for the selection of biocompatible materials, optimization of scaffold/hydrogel component or structure, determination of the release profiles of bioactive reagents, etc. The following will discuss several important aspects in the in vivo studies on OC regeneration.

\section{Materials intrinsic and structural properties}


The intrinsic and structural properties of biomaterials could affect the OC regeneration. The intrinsic properties of biomaterials (such as the purity, chemical groups, molecular weight and monomer ratio) are critical for the immune response of the host cells, the recruitment of the reparative cells, and the formation of new tissues.

Igarashi et al. combined rabbit autologous BMSCs with alginate gels of different grades for the regeneration of rabbit patellar groove OCD for 4 and 12 weeks. ${ }^{51}$ It was found that the ultrapurified alginate group demonstrated better histological and mechanical outcomes compared with commercial alginate groups. Freeze-dried chitosan scaffolds of different molecular weights $(349.3,507.4,510.6,7.9,10.3$, and $11.49 \mathrm{kDa})$ and deacetylation degrees $(91 \%$ and $83 \%)$ were investigated by Abarrategi et al. via implantation them in rabbit medial femoral condyle OCD model for 3 months. ${ }^{52}$ Better subchondral bone regeneration and noticeable cartilaginous tissue regeneration were observed in chitosan scaffolds of intact mineral content, $83 \%$ deacetylation degree and 11.49 kDA molecular weight in contrast with other groups. Jansen et al. compared scaffolds prepared from copolymers comprised of varied poly(ethylene oxide terephthalate) (PEOT) and poly(butylene terephthalate) (PBT) block ratios for OC regeneration in rabbit medial femoral condyle for 12 weeks. ${ }^{53}$ When PEOT/PBT was 70/30, the scaffolds mainly consisted of cartilage-like tissue on top of the trabecular bone. While decreasing the PEOT/PBT ratio to $55 / 45$, the scaffolds comprised mainly of cancellous bone.

Structural properties of biomaterials also play important roles in their in vivo biological performances for OC regeneration, such as porosity, pore size and format. Ikeda et al. compared PLGA scaffolds of different porosities $(80 \%, 85 \%$, and $92 \%)$ by implantation the scaffolds in rabbit patellar groove OCD for 6 and 12 weeks time periods. ${ }^{54}$ It was found that, scaffolds of $85 \%$ and $92 \%$ porosities presented significant higher histological scores than the scaffolds of 
$80 \%$ porosity at both time points. The higher porosity allowed better migration of the MSCs. On the other hand, the pore size effect on OC regeneration was investigated by Duan et al. ${ }^{55}$ Bilayered PLGA scaffolds of the same porosity $(85 \%)$ but with different pore sizes in the chondral and bony layers (50-100 $\mu \mathrm{m}, 100-200 \mu \mathrm{m}, 200-300 \mu \mathrm{m}$ and 300-450 $\mu \mathrm{m})$ were developed. The scaffolds were seeded with allogenic rabbit BMSCs and the constructs were cultured for 7 days before implantation in rabbit femoral condyle for 6 and 12 weeks. They found that pore size between 100-200 $\mu \mathrm{m}$ was beneficial for chondral repair and the one between 300-450 $\mu \mathrm{m}$ was good for bone regeneration. Hui et al. rehydrated the previously freeze-dried OPF hydrogels and then implanted them in load-bearing regions of lateral and medial condyle OCD in 8 months old pigs for 2 and 4 months. ${ }^{49}$ It was found the scaffold induced neotissue filling to $58 \%$ and $54 \%$ after 2 and 4 months, respectively. Newly formed hyaline cartilage made up $39 \%$ of the neotissue after 4 months, but without inducing subchondral bone regeneration.

By analysis of the in vivo study results, we can select the most suitable component and the best structure for further study.

\section{Bioactive scaffolds}

Development of bioactive scaffolds without growth factors is an attractive approach for OC regeneration due to the low cost and simple processing procedure. ECM based scaffold could be a good choice for this purpose. ECM, which is produced by the host cells, contains bioactive molecules for driving tissue regeneration and provides biomimetic microenvironments for cellular homing. There were successful reports on ECM application in clinic, such as cardiovascular and muscle. ${ }^{56,57}$ The ECM based scaffolds can be vitalized or devitalized tissues. 
Emans et al. ectopically created cartilage tissue in periosteum by creating periosteal defects in the tibia of rabbits. ${ }^{58}$ After 14 days, the reactive tissues were harvested and implanted in rabbit medial condyle OCD with and without hyaluronan for 3 weeks and 3 months time periods. Empty defects, defects filled with hyaluronan were used as controls. The results showed that empty defect and hyaluronan groups were far from fully filled, while ectopic cartilage groups with and without hyaluronan were filled to the level of the adjacent cartilage 3 weeks after implantation. After 3 months, empty defects were partially filled with fibrous or fibrocartilaginous tissue, but the ectopic cartilage implanted groups (with or without hyaluronan) were almost fully filled with both fibrocartilaginous and hyaline cartilage. The modified O’Driscoll scores for empty defect and hyaluronan groups were $12.7 \pm 6.4$ and $15.3 \pm 3.2$, and the ectopic cartilage implanted defects without or with hyaluronan were $15.4 \pm 3.9$ and 18.2 \pm 2.9 . Rabbit chondrocytes-derived ECM scaffolds were studied by Jin et al. ${ }^{25}$ Rabbit chondrocytes were cultured for 3 weeks in pellet-type manner. The formed cartilage tissue were freeze-dried and used as scaffolds for culture of rabbit chondrocytes for varied time periods (2-day, 2-week and 4-week groups). The constructs were then applied in OC regeneration in rabbit patellar grooves for 1 and 3 months. Untreated defects were used as control. After 1 month, the 2-week and 4-week groups were repaired with hyaline cartilage like tissue, while fibrocartilage tissues were observed in the control and the 2-day groups. After 3 months, the 4-week group presented striking features of hyaline cartilage, with a mature matrix and a columnar arrangement of chondrocytes. This group also displayed prominently zonal distribution of Col II, the highest International Cartilage Repair Society score among all the groups, and well restored subchondral bone. 
Decellularized OC tissue and non-OC tissues were also used for OC regeneration. Yagihashi et al. filled the rabbit patellar fossa OCD with decellularized bovine dentin matrix (50 or $100 \mathrm{mg}$ per defect) for 1 to 9 weeks. ${ }^{59}$ Untreated defects served as control. After 3 weeks, the $100 \mathrm{mg}$ group had higher new bone formation compared with the other groups, but the difference decreased with time. The 100-mg group showed better cartilage regeneration compared with the other groups, with hyaline cartilage in the peripheral area after 6 weeks and hyaline cartilage with similar thickness to the normal one after 9 weeks. Yang et al. produced a bilayered scaffold consisting of a decellularized cartilage matrix layer (chondral part) and a decellularized cancellous bone matrix layer (bony part). ${ }^{60}$ Canine BMSCs were chondrogenically differentiated for 14 days and then seeded onto the chondral part of the bilayered scaffolds. The constructs were implanted in canine bilateral femoral condyle for 3 and 6 months after in vitro culture for 4 days. Scaffolds without cells were implanted as control. Results displayed that the macroscopic and histological grading scores of the experimental group were always higher than those of the control group. The scores for experimental group after 6 months showed higher values than those after 3 months. The stiffness of the neocartilage and subchondral bone in the experimental group was $70.77 \%$ and $74.95 \%$ of the ones of normal tissues, respectively. GAG content of the experimental group was $84.82 \%$ of the one of native cartilage. Regular and mature subchondral bone formed at both time points in the two groups.

Successful decellularization procedure allows the application of allogeneic or xenogeneic ECM scaffolds for OC regeneration. However, the mechanical properties of the ECM derived scaffolds are normally lower than the ones of the original tissues, due to the decellularization process. Development of composite scaffolds consisting of ECM and other synthetic biomaterials may provide a solution to overcome this limitation. 


\section{Layered scaffolds}

Similar to the in vitro studies, layered scaffolds were investigated intensively for in vivo OC regeneration using acellular or cellular strategy.

In our recent study, bilayered Silk/Silk-NanoCaP scaffolds were developed and implanted in rabbit knee condyle OCD for 4 weeks in an acellular strategy. ${ }^{61}$ Neocartilage formation in the chondral layer and abundant subchondral bone ingrowth in the bony layer of the bilayered scaffolds were observed (Figure 2). Jiang et al. developed bilayered poly(D-lactic acid) (PDLA) (chondral layer) and PDLA/tricalcium phosphate (bony layer) scaffolds. Autologous porcine chondrocytes were seeded into the chondral layer of the bilayered scaffolds and then the constructs were implanted by press-fit method in porcine medial/lateral femoral condyle OCD for 6 months. ${ }^{62}$ Scaffolds without cells served as control. The results of the experimental group showed that the scaffold retained in the center and cancellous bone formed in the periphery of the osseous layer. In the chondral phase, hyaline cartilage regeneration was confirmed by the positive Col II and Safranin O staining. Only fibrous tissue formed in the scaffold alone group. Both groups supported subchondral bone regeneration and mineralization. Shao et al. incorporated allogenic rabbit BMSCs into bilayered PCL and PCL/tricalcium phosphate (TCP) scaffolds by using fibrin gel and then implanted the scaffolds in rabbit medial femoral condyle OCD for 3 and 6 months. ${ }^{63}$ Scaffolds without cells were used as control. The experimental group displayed superior repair results as compared with the control group. Bone regeneration was good and consistent at both time points. After 3 months, all samples presented mixtures of neocartilage tissue and scaffold. After 6 months, some samples showed degradation while others presented normal cartilage appearance. 



Figure 2. Silk based bilayered scaffold for OC regeneration in rabbit femur condyle after implantation for 4 weeks. (A) Macroscopic image of the bilayered scaffold. (B) Masson's trichrome staining of the explants. The black arrows indicate neocartilage formation in the silk layer and the white arrow indicates new subchondral bone formation inside the silk-nanoCaP. (C) Safranin O staining in the silk layer of the explants. It was revealed that abundant GAG and proteoglycan formed in the inner domain of the silk layer. Arrow indicates chondrocytes. (D) Masson's trichrome staining of the silk-nanoCaP layer in the explants. Arrow indicates new vessel formation. (E) Col II staining (fluorescent immunohistochemistry) in the silk layer of the explants. Arrow indicates Col II (red), while scaffold was stained blue. (F) SNA-lectin immunohistochemical staining for the endothelial cells invading the silk-nanoCaP layer. Arrow indicates vessels. "NB', indicates new bone inside the scaffold, " $\mathrm{S}$ ', indicates scaffold. Adapted from Reference (61), with permission from Elsevier. 
Multilayered scaffolds were also studied by in vivo models. ${ }^{50,64,65}$ Tri-layered scaffold was generated by Tampieri et al., which contained an upper layer of collagen/hyaluronan, a lower layer of biomineralized collagen, and a intermediate layer of biomineralized collagen with lower extent of mineral. ${ }^{50}$ The tri-layered structure of the scaffold mimicked the cartilage, tidemark and subchondral bone regions in OC tissue. Ewe BMSCs were seeded onto the scaffolds and the constructs were subcutaneously implanted in nude mice for 8 weeks. The results revealed that cartilaginous matrix deposition was observed only in the loose chondral layer, and bone tissue was only formed in the subchondral layer. In the study from Da et al., one compact PLGA/TCP layer was generated between the porous decellularized bovine cartilage ECM layer (chondral layer) and the porous PLGA/TCP layer (bony layer). ${ }^{64}$ These scaffolds presented superior antitensile and anti-shear properties to the control scaffold without compact layer. Rabbit BMSCs after osteogenic or chondrogenic differentiation for 21 days were seeded onto the bony and chondral parts of the scaffolds, respectively. The constructs after 3 days culture in DMEM were implanted in OCD in rabbit patellofemoral groove for 3 and 6 months. Bilayered scaffolds without compact layer were used as control. The results showed that the higher macroscopic scores, GAG and collagen contents, as well as superior histological results were observed in the scaffolds containing compact layer compared with the control.

\section{Biological cues}

Biological cues have been introduced into the scaffolds for the purpose of enhancing chondrocyte proliferation, or guiding the progenitor cells to mature and subsequently form healthy OC tissues. 
A representative method is the incorporation of growth factors in the scaffolds. Huang et al. combined the basic fibroblast growth factor (bFGF) in the poly(L-lactic acid)/amorphous calcium phosphate (ACP/PLLA) hybrid scaffolds and implanted these scaffolds in rabbit femoral condyle OCD for 4 and 12 weeks. ${ }^{66}$ Untreated defects and PLLA scaffolds incorporated with bFGF were used as controls. The results showed that PLLA group presented better defect filling compared with untreated group. Mainly fibrocartilage and limited bone formation were observed in the PLLA scaffolds. Additionally, only a little amount of Col II and no aggrecan genes were measured for this group. In the case of ACP/PLLA group, most of the defects were filled with well-established cartilage tissue with large amount cartilaginous ECM. Positive Col II staining was observed, and high level of Col II and aggrecan genes were detected.

In order to control the release profile, growth factors could be loaded firstly into microspheres and then incorporated in the scaffolds for OC repair. ${ }^{67,68}$ In the study of Reyes et al., PLGA microsphere incorporating TGF- $\beta 1$ or BMP-2 were loaded in the top alginate layer of the bilayered alginate/PLGA scaffolds. ${ }^{67}$ The bilayered scaffolds with $2.5 \mu \mathrm{g}$ or $5 \mu \mathrm{g}$ BMP-2, or 50 ng TGF- $\beta 1$ in the alginate layer were implanted in rabbit medial condyle OCD for 2, 6, 12 and 24 weeks. Empty defects and unloaded scaffolds served as controls. After 6 weeks, all growth factor-treated groups displayed clear signs of defect repair, with complete repair of subchondral bone and good quality cartilage in most of the cases. In week 12, remarkably regeneration improvements in cartilage were observed between the untreated and growth factor-treated specimens, especially with TGF- $\beta 1$ and $5 \mu \mathrm{g}$ BMP-2 groups. All the growth factor-treated groups exhibited typical hyaline cartilage and regular surface in the defects. The results in week 24 were similar with the ones in week 12 . Kim et al. combined IGF-1and/or TGF- $\beta 3$ loaded gelatin microparticles in the chondral layer of the bilayered OPF hydrogels. ${ }^{69}$ The chondral OPF 
layer was $1 \mathrm{~mm}$ in thickness. Four groups of hydrogels were developed: Control without growth factor; microparticles loaded IGF-1; microparticle loaded IGF-1 and gel-loaded TGF- $\beta 3$; microparticles-loaded IGF-1 and microparticles-loaded TGF- $\beta 3$. The bilayered hydrogels were implanted in rabbit medial femoral condyles for 12 weeks. The results revealed that all the groups showed improvement in cartilage morphology compared with the control. Single delivery of IGF-1 displayed higher scores in subchondral bone morphology, improved chondrocytes and GAG amounts in adjacent cartilage tissue when compared with a dual delivery of IGF-1 and TGF- $\beta 3$.

Gradient growth factors loading strategy was applied for in vivo OC interface regeneration. ${ }^{70}$ ${ }^{71}$ Mohan et al. developed PLGA microsphere based scaffolds with continuous gradients in the loaded growth factors and material composition. ${ }^{71}$ The scaffold was composed of a chondral layer of TGF- $\beta 1$ loaded PLGA microspheres, a bony layer of BMP-2 loaded PLGA or PLGA/HA microspheres, and a gradient transition of the two layers in the middle. Blank PLGA scaffolds and blank gradient PLGA and PLGA/HA scaffolds (without growth factors) were used as controls. The four groups of scaffolds were implanted in rabbit medial condyle OCD for 6 and 12 weeks. The gross morphology, MRI and histology data showed that the greatest extent of regeneration of cartilage and subchondral bone were achieved by the gradient PLGA and PLGA/HA scaffolds with growth factors loading. This group presented similar GAG content and cartilage thickness to the ones of the native cartilage, as well as higher bone filling and better edge integration with host bone compared with the other groups.

The platelet-rich plasma (PRP) contains a pool of growth factors and is considered as a promising alternative to commercial growth factors. ${ }^{72-74}$ Comparison of the PRP scaffolds seeded with BMSCs or ADSCs for OC regeneration was performed by Xie et al. ${ }^{73}$ The cells suspension 
was mixed with PRP first and then the PRP would formed a fibrin clot by the activation of calcium from the medium. The BMSCs/PRP or ADSCs/PRP constructs were cultured in vitro for 3 weeks and also implanted in male rabbit patellar groove OCD for 6, 9 and 12 weeks. PRP alone and untreated defects served as controls. The in vitro results showed that the BMSCs constructs exhibited higher proliferation rate, enhanced expressions of cartilage-specific genes and proteins compared with the ADSCs constructs. Regarding the in vivo study outcomes, the BMSCs seeded scaffolds displayed better gross appearance, histological and immunohistochemical characteristics, higher cartilage-specific genes and protein expressions, and superior subchondral bone regeneration compared with the other groups. This study has thus shown that PRP constructs can induce the differentiation of the seeded ASC into functional chondrocytes in vivo.

Apart from the growth factors, gene delivery was also employed for OC regeneration. Chen et al. generated a plasmid TGF- $\beta 1$ containing chitosan-gelatin scaffold as chondral part and a plasmid BMP-2 loaded HA/chitosan-gelatin scaffold as subchondral bone part. ${ }^{75}$ Rabbit BMSCs were seeded onto the chondral or the osteochondral bone part and the constructs were separately cultured for one week. Afterwards, a bilayered gene-activated scaffold was generated by combining the chondral and subchondral bone constructs with fibrin gel and subsequently the bilayered constructs were cultured in vitro for two weeks. The bilayered constructs were then implanted in rabbit patellar groove OCD for 4, 8 and 12 weeks. Scaffolds without plasmids, mono layer scaffolds with TGF- $\beta 1$ or BMP-2 gene were also implanted. Empty defects were used as control. The in vitro result showed that high level of TGF- $\beta 1$ and BMP-2 protein secretions by the seeded BMSCs were observed in the chondral layer and the subchondral layer, respectively. Regarding the in vivo outcomes, the monolayer scaffolds with BMP-2 gene 
presented complete trabecular bone ingrowth within subchondral bone region and good integration with native bone tissue, but abundant Col I in the cartilage part. The monolayer scaffolds with TGF- $\beta 1$ gene showed similar cartilage surface with native cartilage, while the regeneration of subchondral bone was insufficient. The bilayered scaffolds incorporated with genes simultaneously supported the regeneration of articular cartilage and subchondral bone under a spatially controlled manner after implantation for 12 weeks.

In OC regeneration, the terminal differentiation of BMSCs often brings adverse outcomes. To address this issue, intra-articular injection of parathyroid hormone-related protein (PTHrP) together with implantation of bilayered collagen (chondral layer) and silk-HA (bony layer) scaffolds in rabbit patellar groove OCD for 16 weeks was performed by Zhang et al. ${ }^{76}$ The injection of PTHrP was carried out at three time windows (4-6, 7-9, and 10-12 weeks) every 7 days after implantation. PBS was injected as control. It was found that defects treated with PTHrP at the 4-6 weeks time window exhibited better regeneration (reconstitution of cartilage and subchondral bone), minimal terminal differentiation (hypertrophy, ossification and matrix degradation), as well as enhanced chondrogenesis (cell shape, collagen II, and GAG content), compared with treatments at other time windows and control. The timing also influenced PTHrP receptor expression.

In the future, clinically relevant doses of growth factors or other bioactive factors and possibilities for their controlled release for OC regeneration should be further investigated.

\section{Gene transfection}

The incorporation of bioactive factors in scaffolds for OC regeneration is subject to many complicated aspects, such as carrier properties, encapsulation efficiency and shelf life of the 
drugs. Production of these active factors by the cells is an attractive method. For this purpose, the gene transfer technology has been used for OC regeneration. ${ }^{75,77-84}$

Ueblacker et al. performed the transfection of rabbit chondrocytes with lacZ gene which was fused with tetracycline-responsible element (TRE). ${ }^{84}$ The gene expression of the transfected cells was controlled by the non-toxic drug, such as tetracycline or doxycycline. The transfected cells were seeded into collagen sponges and subsequently implanted in the rabbit femur patellar groove OCD for 4 weeks. The lacZ gene expression can be detected for 3 weeks with doxycycline treatment. The implants were integrated well with the host tissue. This study provided new insights for regulation of gene expression for OCD treatment.

Producing growth factors by engineered cells has been studied. Chen et al. transduced dedifferentiated rabbit chondrocytes with recombinant baculovirus expressing BMP-2 and seeded the engineered cells onto PGA scaffolds. ${ }^{77}$ The scaffolds were cultured in a rotating bioreactor for 0,1 and 3 weeks. The constructs were then implanted into rabbit knee patellar groove OCD for 8 weeks. Mock-transduced constructs without bioreactor culture were implanted as control. In vitro results showed that increased time led to more mature cartilaginous constructs. Regarding the in vivo results, the control group did not showed any repair of the defect. The 0 week constructs (without bioreactor culture) resulted in incomplete regeneration of the defect. The 1 week constructs presented neocartilage layer rich in GAG and Col II, while non-complete integration between the graft and host cartilage. The 3 week constructs displayed regeneration of hyaline cartilage, improved integration, Col II and GAG rich matrixes. Madry et al. transfected the lacZ gene (control) and human IGF-I cDNA to allogenic lapine articular chondrocytes. ${ }^{83}$ The cells were cultured in PGA scaffolds in a rotating bioreactor for 10 or 28 days. The constructs were then implanted into OCD of rabbit knee patellar groove for 28 weeks. It was found that 
engineered cartilage with genetically modified chondrocytes (overexpressing human IGF-I) markedly enhance the repair of OCD compared with the control group. The longer in vitro culture time led to superior OC regeneration outcomes and resulted in significantly decreased osteoarthritic changes in the neighboring tissue of the defects. In the future, more investigations on the optimization of introduced genes, improvement of transfection efficiency, and modulation of the transfected gene expression should be performed.

\section{External stimulus}

Besides the scaffolds, cells and biological cues, the external stimulus (such as mechanical stimulus) is also important for the healing of OC tissues. ${ }^{85,86}$ Chang et al. implanted acellular PLGA scaffolds in rabbit femoral condyle OCD for 4 and 12 weeks. Immobilization (Imm), intermittent active motion (IAM), and continued positive motion (CPM) treatments were performed on the rabbits in the day following the surgery. ${ }^{93}$ Empty defects were used as control. After 12 weeks, the CPM group presented the best outcome with normal articular surfaces and no contracture in the joint. While Imm and IAM groups showed degenerated joints, abrasion cartilage surface and synovitis. The CPM group also showed significantly higher bone volume compared with the other groups. These results implied that the post-surgery physical stimulus synergistically contributed to the healing of OCD. Other external physical treatments are worthy to be explored in OC tissue engineering, such as electrical and magnetic stimuli, acupuncture and so on.

\section{Clinical Studies on OC Tissue Engineering}


Table 1. Clinical Studies on OC Tissue Engineering

\begin{tabular}{|c|c|c|c|}
\hline Scaffolds/Cells & $\begin{array}{l}\text { Defect site } \\
\text { Follow up time } \\
\text { Patient number } \\
\text { Type of study }\end{array}$ & $\begin{array}{l}\text { - Success rate } \\
\Delta \text { Advantages } \\
\nabla \text { Disadvantages }\end{array}$ & Ref \\
\hline $\begin{array}{l}\text { Hyalograft } C \circledR \\
\text { scaffold with human } \\
\text { autologous } \\
\text { chondrocytes } \\
\text { (MACI) }\end{array}$ & $\begin{array}{l}\text { Ankle } \\
12 \text { and } 36 \text { months } \\
46 \\
\text { Prospective }\end{array}$ & $\begin{array}{l}\text { - The preoperative AOFAS score was } \\
57.2 \pm 14.3 \text {. After } 12 \text { and } 36 \text { months, the } \\
\text { scores were } 86.8 \pm 13.4 \text { and } 89.5 \pm 13.4 \text {, } \\
\text { respectively. } \\
\Delta \quad \text { The histological staining (blinded } \\
\text { analysis) revealed that hyaline-like cartilage } \\
\text { was formed. }\end{array}$ & 20 \\
\hline $\begin{array}{l}\text { Biphasic collagenous } \\
\text { scaffold with } \\
\text { autologous } \\
\text { chondrocytes } \\
\text { (MACI) }\end{array}$ & $\begin{array}{l}\text { Knee } \\
6 \text { and } 12 \text { months } \\
30 \\
\text { Prospective }\end{array}$ & $\begin{array}{l}\text { - The IKDC scores increased from } 24 \text { to } 44 \\
\text { and } 66 \text { after } 6 \text { months and } 1 \text { year post- } \\
\text { operation, respectively. The MOCART score } \\
\text { (blinded analysis) was improved from } 11.5 \\
\text { ( } 6 \text { months) to } 13 \text { (1 year). } \\
\Delta \text { Good clinical results were achieved even } \\
\text { when MACI as a second-line procedure. }\end{array}$ & 87 \\
\hline $\begin{array}{l}\text { Col I/III bilayered } \\
\text { membrane with } \\
\text { autologous } \\
\text { chondrocytes } \\
\text { (MACI) }\end{array}$ & $\begin{array}{l}\text { Ankle } \\
1 \text { and } 2 \text { years } \\
10 \\
\text { Prospective }\end{array}$ & $\begin{array}{l}\text { - The AOFAS scores increased from } 61.2 \\
\text { (preoperative, ranged from 42-76) to } 74.7 \text { (1 } \\
\text { year postoperative, ranged from 46-87) and } \\
73.3 \text { ( } 2 \text { year postoperative, ranged from } 42- \\
90 \text { ). } \\
\Delta \text { MACI may be an effective treatment for } \\
\text { full-thickness lesions in talus without } \\
\text { malleolar osteotomy. }\end{array}$ & 89 \\
\hline $\begin{array}{l}\text { Porcine Col I } \\
\text { scaffold with } \\
\text { autologous } \\
\text { chondrocytes } \\
\text { (MACI) }\end{array}$ & $\begin{array}{l}\text { Ankle } \\
\text { Mean } 24.5 \text { months } \\
18 \\
\text { Prospective }\end{array}$ & $\begin{array}{l}\text { - For AOFAS score, } 64 \% \text { were rated as } \\
\text { excellent/good, whereas } 36 \% \text { were rated } \\
\text { fair/poor. The FFI pain and disability, } \\
\text { AOFAS, AAOS scores were } 5.5 \pm 2.0,5.0 \pm \\
2.3,58.6 \pm 16.1 \text { and } 59.9 \pm 16.0 \text { before } \\
\text { MACI. After MACI, these scores were } 28 \pm \\
2.2,2.6 \pm 2.2,80.4 \pm 14.1 \text { and } 83.5 \pm 13.2 \text {, } \\
\text { respectively. MOCART score (blinded } \\
\text { analysis) was } 62.4 \pm 15.8 \text {. } \\
\Delta \text { MACI is a safe procedure for the } \\
\text { treatment of OCD in the ankle. }\end{array}$ & 90 \\
\hline $\begin{array}{l}\text { Type I/III Col } \\
\text { membrane with } \\
\text { autologous } \\
\text { chondrocytes } \\
\text { (MACI) }\end{array}$ & $\begin{array}{l}\text { Knee } \\
1 \text { year } \\
5 \\
\text { Prospective }\end{array}$ & $\begin{array}{l}\text { Pain reduction and significant } \\
\text { improvement in function were observed after } \\
\text { the MACI. }\end{array}$ & 85 \\
\hline
\end{tabular}


Table 1. Continued (1)

\begin{tabular}{|c|c|c|c|}
\hline Scaffold/Cell & $\begin{array}{l}\text { Defect site } \\
\text { Follow up Time } \\
\text { Patient number } \\
\text { Type of study }\end{array}$ & $\begin{array}{l}\text { - Success rate } \\
\boldsymbol{\Delta} \text { Advantages } \\
\nabla \text { Disadvantages }\end{array}$ & Ref \\
\hline $\begin{array}{l}\text { Col powder or } \\
\text { hyaluronan } \\
\text { membrane loaded } \\
\text { with concentrated } \\
\text { BMSCs } \\
\text { (MASI) }\end{array}$ & $\begin{array}{l}\text { Ankle } \\
6,12,18 \text { and } 24 \\
\text { months } \\
23 \text { (Col) } \\
25 \text { (Hyaluronan) } \\
\text { Prospective }\end{array}$ & $\begin{array}{l}\text { - In Col group, the AOFAS score was } \\
62.5 \pm 18 \text { pre-operation and increased to } \\
89.8 \pm 9.8,24 \text { months post-operation. In the } \\
\text { hyaluronan group, the scores increased from } \\
66.2 \pm 10.5 \text { to } 92.8 \pm 5.3,24 \text { months post- } \\
\text { operation. } \\
\text { BMSCs, One-step procedure using concentrated } \\
\text { BMSCsfolds and platelet gel for OCD } \\
\text { treatment. MRI showed restoration in } \\
\text { cartilage and subchondral bone after } 2 \text { years. }\end{array}$ & 24 \\
\hline Trufit $\AA$ & $\begin{array}{l}\text { Patella } \\
6 \text { to } 24 \text { months } \\
10 \\
\text { Prospective }\end{array}$ & $\begin{array}{l}\text { - After one year follow-up, the results were } \\
\text { satisfactory in } 80 \% \text { patients. } \\
\text { A One-step procedure for OCD treatment. } \\
\text { suffer } 18 \text { months follow up, } 9 \text { patients } \\
\text { Reoperation rate for implant failure reached } \\
70 \% \text {. MRI screened at final follow up } \\
\text { showed a cylindrical cavity of fibrous tissue } \\
\text { instead of subchondral bone ingrowth. }\end{array}$ & 21 \\
\hline $\begin{array}{l}\text { Multilayered } \\
\text { scaffold contains } \\
\text { PLGA, PGA, and } \\
\text { calcium sulphate } \\
\text { (Trufit BGS } ® \text { plug) }\end{array}$ & $\begin{array}{l}\text { Knee } \\
6-39 \text { months } \\
26\end{array}$ & $\begin{array}{l}\Delta \text { The plug demonstrated flush morphology } \\
\text { at early ( } \leq 6 \text { months) and longer follow-up } \\
\text { ( } \geq 16 \text { months), T2 relaxation times of the } \\
\text { plug approached those of normal articular } \\
\text { cartilage at longer follow up. } \\
\nabla \quad \text { The plug presented deteriorated } \\
\text { appearance at } \sim 12 \text { months follow-up. }\end{array}$ & 88 \\
\hline Trufit BGS® plug & $\begin{array}{l}\text { Knee (donor sites } \\
\text { after subchondral } \\
\text { transplantation) } \\
\text { 2-63 months } \\
9\end{array}$ & $\begin{array}{l}\text { - Post-operation, the CT scan showed } \\
\text { decrease in the House Units from } 84 \text { ( } 4 \\
\text { months) to } 19 \text { ( } 13 \text { months). The ossification } \\
\text { quality score was } 1 \text { (soft-tissue density) } \\
\text { instead of } 4 \text { (cancellous bone). } \\
\text { No evidence of bone ingrowth, } \\
\text { ossification or osteoconductivity. The } \\
\text { density of the donor sites declined over time. }\end{array}$ & 91 \\
\hline Trufit $\AA$ plug & $\begin{array}{l}\text { Knee } \\
6 \text { and } 12 \text { months } \\
20 \\
\text { Prospective }\end{array}$ & $\begin{array}{l}\Delta \text { The short-term clinical and MRI results } \\
\text { were modest. No deterioration of the } \\
\text { repaired tissue was observed. } \\
\nabla 3 \text { of the } 15 \text { patients failed and had to } \\
\text { undergo autologous OC transplantation. }\end{array}$ & 94 \\
\hline
\end{tabular}


Table 1. Continued (2)

\begin{tabular}{|c|c|c|c|}
\hline Scaffold/Cell & $\begin{array}{l}\text { Defect site } \\
\text { Follow up Time } \\
\text { Patient number } \\
\text { Type of study }\end{array}$ & $\begin{array}{l}\text { - Success rate } \\
\boldsymbol{\Delta} \text { Advantages } \\
\nabla \text { Disadvantages }\end{array}$ & Ref \\
\hline $\begin{array}{l}\text { Multilayered nano- } \\
\text { composite scaffold } \\
\text { containing Col and } \\
\text { Col/HA scaffold } \\
\text { (MaioRegen }())\end{array}$ & $\begin{array}{l}\text { Knee } \\
6 \text { months } \\
13 \text { (15 defects) } \\
\text { Prospective }\end{array}$ & $\begin{array}{l}\text { - } 4-5 \text { weeks post-operation, } 86.7 \% \text { lesions } \\
\text { were of completely attached graft and repair } \\
\text { tissue. Complete filling of the cartilage } \\
\text { defect and congruency of the articular } \\
\text { surface were seen in } 10 \text { defects after } 6 \\
\text { months. } 13.3 \% \text { detachment was observed. } \\
\text { Histological analysis showed the } \\
\text { formation of subchondral bone without the } \\
\text { presence of materials. } \\
\nabla \text { Oedema or sclerosis in subchondral bone } \\
\text { was presented in } 8 \text { defects. }\end{array}$ & 22 \\
\hline MaioRegen $\AA$ & $\begin{array}{l}\text { Knee } \\
6,12, \text { and } 24 \\
\text { months } \\
30 \\
\text { Prospective }\end{array}$ & $\begin{array}{l}\text { - IKDC objective score changed from } \\
50.0 \% \text { (preoperation) to } 96.4 \% \text { and } 85.7 \% \\
\text { at } 12 \text { and } 24 \text { months follow up, } \\
\text { respectively. The mean Tegner score was } \\
1.6 \pm 1.1 \text { preoperative, } 4.0 \pm 1.6 \text {, and } 4.0 \pm 1.8 \\
\text { at the } 12 \text { months and after } 2 \text { years follow } \\
\text { up. Complete filling of the cartilage and } \\
\text { integration of the graft were observed in } \\
70 \% \text { of the lesions. } \\
\nabla \text { Only } 7 \% \text { of the subchondral lamina and } \\
47 \% \text { of the bone were considered intact. }\end{array}$ & 92 \\
\hline $\begin{array}{l}\text { MaioRegen }{ }^{\circledR} \\
\text { and HYAFF® }-11\end{array}$ & $\begin{array}{l}\text { Knee } \\
\text { 2-3 years } \\
\text { 8(MaioRegen } \AA) \\
\text { 7(HYAFF®-11) }\end{array}$ & $\begin{array}{l}\text { - When MaioRegen }{ }^{\circledR} \text { was used, the IKDC } \\
\text { score improved from around } 40 \\
\text { (preoperation) to around } 80 \text { (postoperation). } \\
\text { The Tegner score also increased } \\
\text { significantly after the implantation. In case } \\
\text { of HYAFF® }-11 \text {, both the IKDC and } \\
\text { Tegner scores were significantly improved. }\end{array}$ & 95 \\
\hline $\begin{array}{l}\text { Bilayered } \\
\text { PLGA/PLGA-TCP } \\
\text { scaffolds with a } \\
\text { chamber between the } \\
\text { two layers loading } \\
\text { autologous } \\
\text { chondrocytes }\end{array}$ & $\begin{array}{l}\text { Knee } \\
3,6,12 \text {, and } 24 \\
\text { months } \\
10 \\
\text { Prospective }\end{array}$ & $\begin{array}{l}\text { - Postoperative KOOS in "symptoms" only } \\
\text { significantly higher than the pre-operative } \\
\text { value after } 24 \text { months. Whereas the other } \\
\text { four subscales of KOOS were significantly } \\
\text { higher than pre-operation values after } 12 \\
\text { and } 24 \text { months. } \\
\text { A Defects were completely filled and } \\
\text { regenerated cartilaginous surfaces flushed } \\
\text { with surrounding native joint surface. The } \\
\text { regenerated cartilage appeared hyaline. }\end{array}$ & 96 \\
\hline
\end{tabular}


Tissue engineering approaches have already shown its charm in clinical OC regeneration. Table 1 summarized the clinical studies on OC tissue engineering. ${ }^{20-22,24,87-96}$ These approaches include MACI, matrix-associated stem cell implantation (MASI) and layered scaffold implantation.

\section{$M A C I$ and MASI}

MACI is the first application of tissue engineering for $\mathrm{OC}$ regeneration. ${ }^{97}$ For this procedure, autologous chondrocytes are combined with scaffolds first and subsequently implanted into the defects. Collagen and hyaluronic acid scaffolds have been widely used in MACI. These materials are superior regarding their biodegradation, biocompatibility and low immune response. However, they are disadvantageous for the weak mechanical properties.

Comparing with ACI, MACI is advantageous in minimizing the donor site and getting rid of periosteal harvesting and suturing. Some clinical studies showed that MACI is an efficient method for OCD treatments, both in ankle and knee lesions. ${ }^{20,87}$ Giannini et al. showed that the hyaluronan scaffold and specifically designed instrumentation allowed arthroscopic implantation of chondrocytes in the ankle. ${ }^{20}$ In a study from Giza et al, MRI images (blinded analysis) showed the regeneration of articular cartilage and subchondral bone in a 19-months follow up after MACI using the collagen scaffolds. ${ }^{89}$ Even though there are many successful cases on MACI, the clinical results of this approach are significantly related with the quality of chondrocytes used and the patients' conditions. Normally, the cells harvested in this method are of low yield and present limited long-term survival and regenerative capacity, specifically those from the elder patients. ${ }^{98}$ Pietschmann et al. reported that the morphologically abnormal cells led to the poor clinical outcome in MACI. ${ }^{87}$ Aurich et al. also mentioned that the age of the patient and the duration of symptoms had significant impacts on the clinical outcomes. ${ }^{90}$ Similar to ACI procedure, MACI also requires the harvesting of chondrocytes from cartilaginous tissue which 
would induce secondary morbidity and increase the cost. Considering the limitation of autologous chondrocytes, other cell sources might be used as alternative, such as stem cells.

MASI has been explored as an alternative to MACI. In this method, the autologous chondrocytes are replaced by autologous stem cells, e.g. BMSCs or ADSCs. ${ }^{98}$ This new technology requires only a single operation and minimizes the invasion. Nejadnik et al. compared the clinical outcomes of autologous chondrocyte and BMSCs for cartilage regeneration (observational cohort study), and found that there were no differences in the two groups. ${ }^{99}$ Interestingly, they also found that the younger patients showed better outcomes in the ACI group, while the age did not make differences in the BMSCs group. Scaffolds seeded with concentrated bone marrow-derived cells were also investigated for OC regeneration in clinical trials. $^{24}$ In another study, Kon et al. confirmed that the one-step bone marrow derived cell transplantation technology achieved good clinical and radiographic outcomes for patients with osteochondritis dissecans. ${ }^{95}$ Besides BMSCs and ADSCs, there are also other stem cells which are worthy to be explored, such as stem cells from synovium, muscle, amnionic fluid, umbilical cord blood, Wharton jelly and so on.

\section{Layered scaffolds}

The MACI and MASI approach focus on the regeneration of cartilage layer in OCD, and indeed they have demonstrated effectiveness for this purpose. While recent 5-year MRI follow-up showed that subchondral bone diseases (such as edema, cysts, sclerosis, and granulation) were observed in $50 \%$ of the patients who underwent MACI. ${ }^{3}$ This addresses the need for regeneration of subchondral bone together with the regeneration of cartilage layer in OC healing. Layered scaffolds, which mimics the structure and matrix component of OC tissue, provides a promising 
option to overcome this problem. ${ }^{26}$ The implantation of layered scaffolds in OCD only requires one surgery and no need for fixation.


Figure 3. Biomimetic osteochondral scaffolds for clinical application (MaioRegen ${ }^{\circledR}$ ). (A) Scaffolds morphology and components. (B-D) Images showing the surgical procedure: (B) cutting the scaffold, (C) the scaffold is templated using an aluminum foil to obtain the exact size of the graft needed, (D) implantation of the scaffold using a press-fit technique. Adapted from References (12) and (22), with permissions from SAGE and Elsevier, respectively.

Currently, there are three artificial cell-free layered scaffolds available for clinical implantation in OCD: Trufit ${ }^{\circledR}$ CB plug, MaioRegen ${ }^{\circledR}$, and Chondromimetic ${ }^{\circledR}$. Trufit ${ }^{\circledR}$ CB plug is a cylindrical porous scaffold containing poly(lactic-co-glycolic acid) (PLGA), poly(glycolic acid) fiber and calcium sulfate. It is a press-fit implant, with tunable length and diameter ranging from 
5 to $11 \mathrm{~mm}^{88}$ MaioRegen ${ }^{\circledR}$ is a biomimetic three layer scaffold (Figure 3). The composition from the top layer to the bottom layer resembles the contents of collagen and hydroxyapatite in the cartilage, tidemark and the subchondral bone, respectively. ${ }^{22}$ Chondromimetic $\AA$ is bilayered porous implant containing collagen, glycosaminoglycan, and calcium phosphate. ${ }^{100}$ There are no clinical reports on this product yet. Comparing these three scaffolds, Trufit ${ }^{\circledR}$ CB plug composed of synthetic polymers may exhibit better mechanical properties than the other two scaffolds which mainly contain natural macromolecules. Good mechanical properties allow easy implantation and fixation of the scaffolds. On the other hand, the MaioRegen ${ }$ and Chondromimetic $\AA$ may display superior biocompatibility to Trufit ${ }^{\circledR}$ in terms of their degradation products and ability to guide cells' differentiation. Table 1 listed the clinical outcomes of Trufit ${ }^{\circledR}$ and MaioRegen ${ }^{\circledR}$. Both satisfactory and negative results were achieved. These varied clinical outcomes of the layered scaffolds may be related to the patients' conditions (e.g., age, the site of lesion, the type and history of injury) and the intrinsic properties of the biomaterials. More evidences and further comparative studies are required to understand and relate all these aspects.

Attempt combining layered scaffolds and autologous chondrocytes was performed by Chiang et al. ${ }^{96}$ Besides the healing of cartilage, it was also found that cancellous bone formed in the osseous phase without pre-seeding of cells. The biphasic scaffolds seeded with therapeutic autologous cells could be promising strategy for the treatment of OCD in the following. Specific cells might be loaded onto the corresponding layers, respectively. In order to circumvent the limitation of chondrocytes, cells derived from other sources could be used, e.g. ADSCs and BMSCs. 


\section{Challenges and Future Perspectives in OC Tissue Engineering}

Based on the amount of information gathered over the last few years while searching for effective strategies for OC regeneration, it is possible to comprehend the degree of complexity of this task and its limitations (Scheme 1).

\begin{tabular}{|c|c|c|}
\hline & \multicolumn{2}{|c|}{ OC Tissue Engineering } \\
\hline & Strategies & Challenges \\
\hline \multirow{4}{*}{$\begin{array}{l}\text { Clinical } \\
\text { strategies }\end{array}$} & $\mathrm{MACl}$ & $\begin{array}{l}\text { Two operations; fixation problem; donor site morbidity; non-sufficient } \\
\text { subchondral bone regeneration. }\end{array}$ \\
\hline & MASI & $\begin{array}{l}\text { Multi-steps on blood and bone marrow collection, platelet gel formation, } \\
\text { and bone marrow concentration; Fixation problem; non-sufficient } \\
\text { subchondral bone regeneration. }\end{array}$ \\
\hline & Layered scaffold without cells & $\begin{array}{l}\text { Clinical results are preliminary; the influence of scaffold properties on } \\
\text { long-term regeneration outcomes needs to be validated. }\end{array}$ \\
\hline & $\begin{array}{l}\text { Combination of } \mathrm{MACl} \text { and layered } \\
\text { scaffold }\end{array}$ & $\begin{array}{l}\text { Donor site morbidity; clinical results are preliminary; the long-term } \\
\text { regeneration outcomes and influence of scaffold properties need to be } \\
\text { validated. }\end{array}$ \\
\hline \multirow{3}{*}{$\begin{array}{l}\text { Pre-clinical } \\
\text { strategies }\end{array}$} & Single layer or layered scaffold alone & $\begin{array}{l}\text { Interaction between OCD regeneration outcomes and scaffolds } \\
\text { properties (morphology, component, degradation...) or external } \\
\text { stimulus (mechanical, chemical...) still needs to be elucidated. }\end{array}$ \\
\hline & $\begin{array}{l}\text { Single layer or layered scaffold with } \\
\text { cells }\end{array}$ & $\begin{array}{l}\text { The influence of scaffolds properties (morphology, chemical } \\
\text { components...) on the cells phenotype or differentiation is not fully } \\
\text { understood; controlling the cell fate is still a substantial hindrance. }\end{array}$ \\
\hline & $\begin{array}{l}\text { Single layer or layered scaffold with } \\
\text { GF/Bioactive agents alone or } \\
\text { GF/Bioactive agents and cells }\end{array}$ & $\begin{array}{l}\text { The incorporation dose and release profile of GF/Bioactive agents } \\
\text { need to be optimized; The long-term cells fate and regeneration } \\
\text { outcome need to be validated. }\end{array}$ \\
\hline
\end{tabular}

Scheme 1. Current tissue engineering strategies and challenges for OC regeneration. For preclinical strategies, "scaffold" indicated porous scaffold or hydrogels with single layer or layered structure.

In the future, the development of novel bioactive and biomimetic scaffolds for OC regeneration will remain a major issue. The ideal scaffold are those which can be easily integrated with host tissue and include signals to guide the proliferation and differentiation of specific cells to form normal stratified OC tissue. In order to provide a satisfactory environment for the fast formation of OC tissue, the components in the chondral and the subchondral layers of the scaffold should 
resemble the ones in the counterpart of the OC tissue. Additionally, it is important that the structure and components of the scaffolds favor the continuous and integrated OC interface generation. Moreover, the scaffold must maintain its structural integrity when implanted and present a degradation profile matching the growth pace of the de novo tissues. During the regeneration, the scaffolds should be capable of preventing the invasion of synovial fluid to the subchondral bone and the vascularization in the chondral layer.

To address these challenges, ECM-based biomaterials or synthetic ECM analogues are suitable components for scaffold preparation. In order to modulate the mechanical properties and degradation behavior of the scaffolds, controlling the conformations or the assembly process of biomacromolecules, introduction of degradable polymer as a reinforcing phase and regulation of the component ratios, are promising approaches. For the purpose of creating stratified and integrated OC tissue, layered scaffold with gradient transition in the varied phases is the optimal choice. Advanced processing methods are required to spatially control the structure and compositions in the scaffolds, specifically in the interface region.

Since OCD is varied in each individual patient, the customized design of the scaffolds for patients is of great demand. For the generation of customized OC grafts in the in vitro system, please see previous review from Grayson et al. ${ }^{17}$ Nowadays, the computer-aided design and computer aided manufacture (CAD/CAM) technologies provide possibility to built scaffolds for specific individuals, no matter the shape and size of the defects (Figure 4). ${ }^{101,102}$ In the following, these techniques should be used for the preparation of scaffolds from various materials (or composite), and even including bioactive factors and/or stem cells for clinical application. Before being transferred to the clinic, there are still many problems which should be solved, such as optimization of the clinically related incorporation dose and release profile of the 

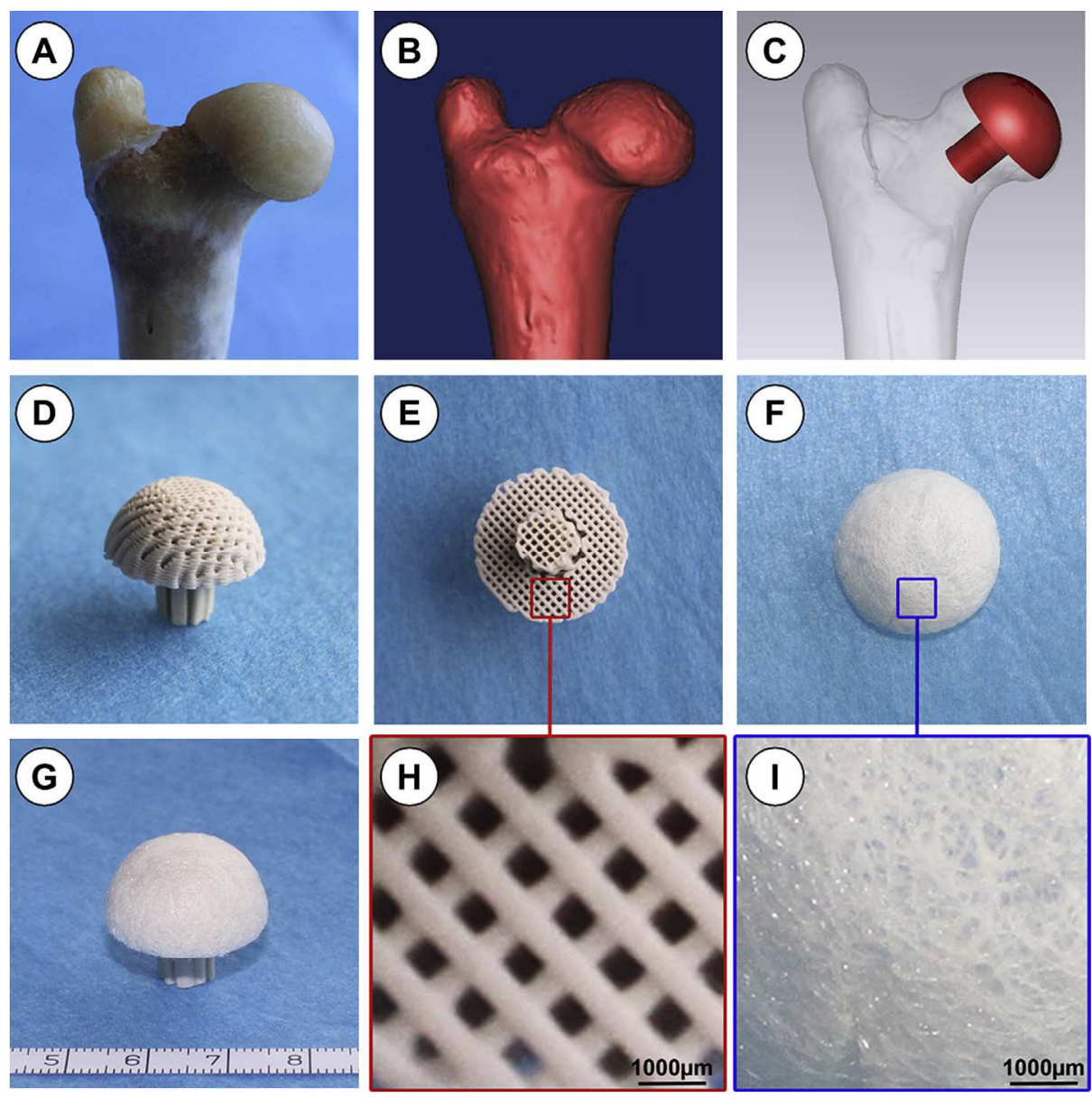

Figure 4. Fabrication of customized biphasic scaffolds using CAD/CAM technology. The morphological information of the goat femoral head (A) was captured by laser scanning. The 3D data were reconstructed via the CAD software $(\mathrm{B}, \mathrm{C})$. PCL/HA scaffold $(\mathrm{D}, \mathrm{E})$ fabricated by fused deposition modeling (FDM) was designed to be with an intramedullary stem and interconnecting microchannels (H). The PGA/PLA scaffold (F) with relatively small pore size (I) was pressed into a hemispherical shape. The well-matched PGA/PLA scaffold and PCL/HA 
scaffold formed a biphasic scaffold (G). Adapted from Reference (101), with permission from Elsevier.

consideration, since non-invasive techniques (preferred by surgeons nowadays) imply dimensional constrains to the materials.

The selection of proper cells for OC regeneration constitutes another critical issue. Adult chondrocytes possess limited regenerative capacity and often undergo dedifferentiation. Adult stem cells are attractive cell sources, while still require invasive harvesting process and are associated with quality instability and low quantity. Other immature stem cells (such as AFSC and UCMSCs) present superior activity and differentiation ability as compared to adult stem cells, but there is a limited access to these cells. Embryonic stem cells (ESCs) possess unlimited differentiation capacity and have been used for cartilage regeneration. ${ }^{103}$ However, their application is still under ethical argument.

Recently, induced pluripotent stem cells (iPSCs), as an alternative to ESCs, have been investigated intensively. ${ }^{104}$ Different from the ESCs, iPSCs can be created from somatic cells and thus circumvent the ethical controversy of ESCs. The utility of iPSCs cells for OC regeneration is promising. Ko et al. at first compared the in vitro chondrogenic differentiation differences of human iPSCs (hiPSCs) and human BMSCs, and then applied the alginate gels encapsulating hiPSCs pellet or hiPSCs for OCD regeneration in the patellar groove of immunosuppressed rat for 12 weeks (Figure 5). ${ }^{105}$ Empty defects and defects filled alginate gels were used as controls. After in vitro culture for 21 days, the chondrogenic hiPSCs showed greater GAG contents and superior chondrocytic characteristics, significantly lower level of Col $\mathrm{X}$ and Col I compared with the chondro-induced BMSCs. Defects filled by alginate gels 
A
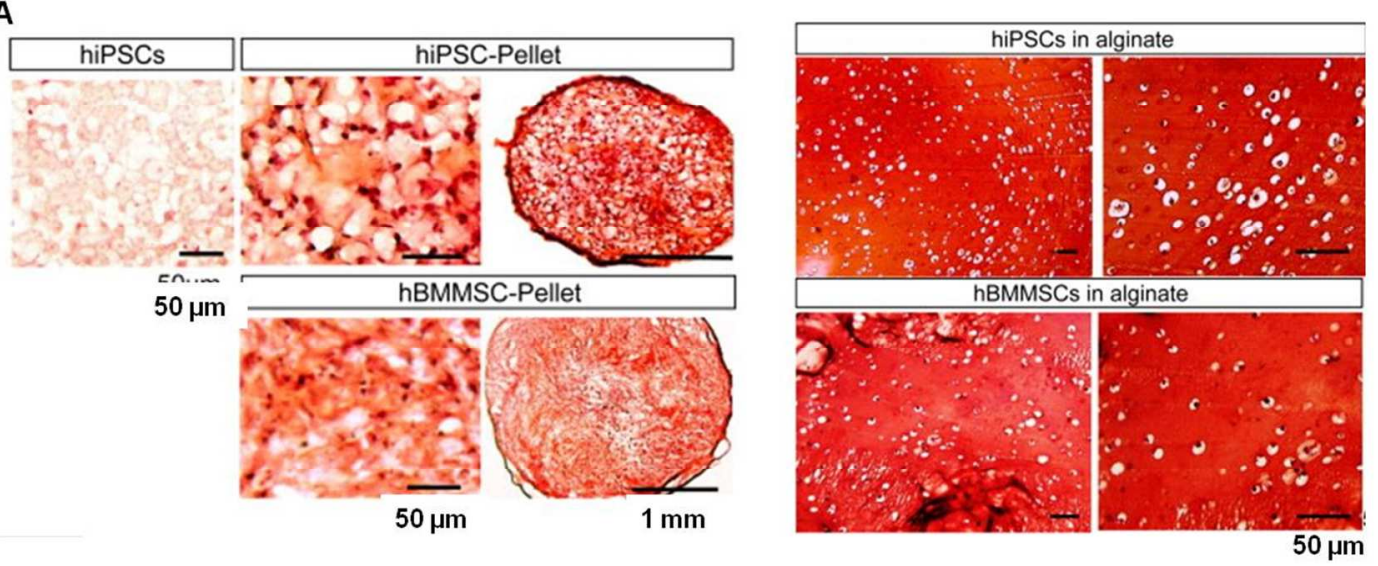



Alginate

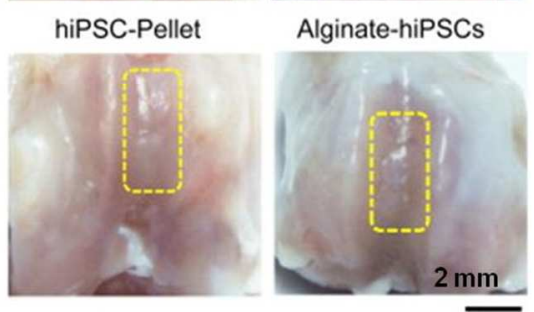

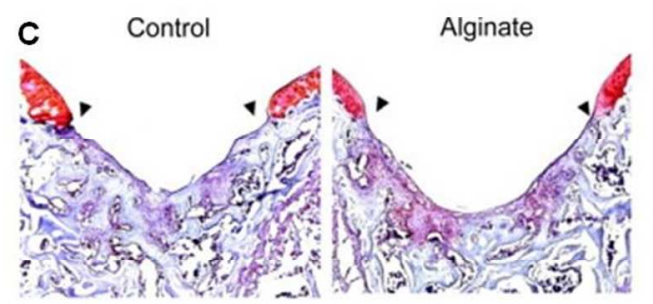

hiPSC-Pellet Alginate-hiPSCs

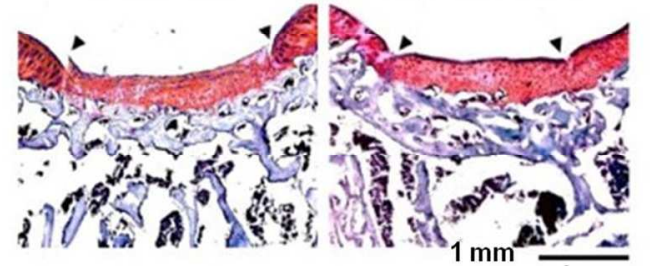

Figure 5. The application of human induced pluripotent stem cells (hiPSCs) for OC regeneration. (A) Safranin O staining of chondro-induced hiPSCs and human BMSCs (pellets and in alginate hydrogel) after 21 days. (B) In vivo repair of patellar OCD in immunosuppressed 
rat after the implantation of chondro-induced hiPSCs for 12 weeks. Safranin O staining confirmed the cartilage regeneration in the hiPSCs containing groups. Adapted from Reference (105), with permission from Elsevier.

\section{Conclusions}

During the past few years, numerous advances have been achieved in OC tissue engineering. Tissue engineering strategies, despite introducing more complexity and details to the current treatments, present a high potential for $\mathrm{OC}$ regeneration. In fact, $\mathrm{OC}$ regeneration is an interdisciplinary topic and integrative strategy should be employed. High-throughput approaches may be applied in rapid materials screening, molecule tailoring, component combinations and structure optimizations for scaffold design. It would be helpful to create novel in vitro culture models (such as using bioreactors) and in vivo animal models which closely mimic the OC microenvironment of the patients, and then test different constructs in these systems and thus establish relationship of these results for guiding the clinical treatment. Although there are still many critical problems to be solved, tissue engineering still represents the most promising alternative for OC regeneration.

\section{Acknowledgements}

The authors thank Portuguese Foundation for Science and Technology (FCT) through the projects TISSUE2TISSUE (PTDC/CTM/105703/2008) and OsteoCart (PTDC/CTMBPC/115977/2009). We also acknowledge European Union's Seventh Framework Programme (FP7/2007-2013) under grant agreement $n^{\circ}$ REGPOT-CT2012-316331-POLARIS. Le-Ping Yan acknowledges the PhD scholarship from FCT (SFRH/BD/64717/2009). The FCT distinction 
attributed to J.M. Oliveira and A.L. Oliveira under the Investigator FCT program (IF/00423/2012) and (IF/00411/2013) are also greatly acknowledged.

\author{
Abbreviations \\ AAOS: The American Academy of Orthopaedic Surgeons; \\ ACI: Autologous chondrocyte implantation; \\ ACP: Amorphous calcium phosphate; \\ AFSCs: Amniotic fluid-derived stem cells; \\ AOFAS: The American Orthopaedic Foot and Ankle Society; \\ ADSCs: Adipose tissue-derived stem cells; \\ bFGF: Basic fibroblast growth factor; \\ $\beta$-GP: $\beta$-glycerol phosphate; \\ BMP-2: Bone morphogenetic protein-2; \\ BMSCs: Bone marrow-derived stem cells; \\ CAD: Computer-aided design; \\ CAM: Computer-aided manufacture; \\ CaP: Calcium phosphate; \\ Col: Collagen; \\ CPM: Continued positive motion; \\ DMEM: Dulbecco's modified Eagle's medium; \\ ECM: Extracellular matrix; \\ ESCs: Embryonic stem cells; \\ FBS: Fetal bovine serum;
}


FDM: Fused deposition modeling;

FFI: The Foot Function Index;

GAG: Glycosaminoglycan;

HA: Hydroxyapatite;

hBMSCs: Human BMSCs;

IGF-1: Insulin-like growth factor-1;

IKDC: International Knee Documentation Committee;

IAM: Intermittent active motion;

Imm: Immobilization;

iPSCs: Induced pluripotent stem cells;

KOOS: Knee injury and Osteoarthritis Outcome Score;

MACI: Matrix-associated chondrocyte implantation;

MASI: Matrix-associated stem cells implantation;

Micro-CT: Micro-computed tomography;

MMP-13: Matrix metalloproteinase-13;

MOCART: Magnetic Resonance Observation of Cartilage Repair Tissue;

MRI: Magnetic resonance imaging;

MSCs: Mesenchymal stem/stromal cells;

OATS: Osteochondral autograft transplantation;

OC: Osteochondral;

OCD: Osteochondral defects;

OLTs: Osteochondral lesion of the talus;

OPF: Poly(ethylene glycol) fumarate hydrogels; 
PBT: Poly(butylene terephthalate);

PCL: Poly( $\varepsilon$-caprolactone);

PDLA: Poly(D-lactic acid);

PLLA: Poly(L-lactic acid);

PEOT: Poly(ethylene oxide terephthalate)

PGA: Poly(glycolic acid);

PLGA: Poly(lactic-co-glycolic acid);

PRP: Platelet-rich plasma;

PTHrP: Parathyroid hormone-related protein;

Ref: Reference;

rhBMP: Recombinant human BMP;

rhIGF: Recombinant human insulin-like growth factor;

SF-36: Patient outcome scores;

TCP: Tricalcium phosphate;

TGF- $\beta 1$ : Transforming growth factor- $\beta 1$;

TGF- $\beta 3$ : Transforming growth factor- $\beta 3$;

TRE: Tetracycline-responsible element;

UCMSCs: Umbilical cord mesenchymal stromal cells.

\section{References}

(1) Moutos, F. T.; Freed, L. E.; Guilak, F. A biomimetic three-dimensional woven composite scaffold for functional tissue engineering of cartilage. Nat Mater 2007, 6, 162-167. 
(2) Mano, J. F.; Reis, R. L. Osteochondral defects: present situation and tissue engineering approaches. J Tissue Eng Regen Med 2007, 1, 261-273.

(3) Gomoll, A. H.; Madry, H.; Knutsen, G.; van Dijk, N.; Seil, R.; Brittberg, M.; Kon, E. The subchondral bone in articular cartilage repair: current problems in the surgical management. Knee Surg Sports Traumatol Arthrosc 2010, 18, 434-447.

(4) Zengerink, M.; Struijs, P. A.; Tol, J. L.; van Dijk, C. N. Treatment of osteochondral lesions of the talus: a systematic review. Knee Surg Sports Traumatol Arthrosc 2010, 18, 238246.

(5) Weil, L., Jr. Biologics in foot and ankle surgery. Foot Ankle Spec 2011, 4, 249-252.

(6) Lee, B. J.; Christino, M. A.; Daniels, A. H.; Hulstyn, M. J.; Eberson, C. P. Adolescent patellar osteochondral fracture following patellar dislocation. Knee Surg Sports Traumatol Arthrosc 2013, 21, 1856-1861.

(7) Bitton, R. The economic burden of osteoarthritis. Am J Manag Care 2009, 15, S230-235.

(8) Minas, T.; Gomoll, A. H.; Rosenberger, R.; Royce, R. O.; Bryant, T. Increased failure rate of autologous chondrocyte implantation after previous treatment with marrow stimulation techniques. Am J Sports Med 2009, 37, 902-908.

(9) Kreuz, P. C.; Steinwachs, M. R.; Erggelet, C.; Krause, S. J.; Konrad, G.; Uhl, M.; Sudkamp, N. Results after microfracture of full-thickness chondral defects in different compartments in the knee. Osteoarthr Cartilage 2006, 14, 1119-1125.

(10) Espregueira-Mendes, J.; Pereira, H.; Sevivas, N.; Varanda, P.; da Silva, M. V.; Monteiro, A.; Oliveira, J. M.; Reis, R. L. Osteochondral transplantation using autografts from the upper tibio-fibular joint for the treatment of knee cartilage lesions. Knee Surg Sports Traumatol Arthrosc 2012, 20, 1136-1142. 
(11) Hangody, L.; Dobos, J.; Balo, E.; Panics, G.; Hangody, L. R.; Berkes, I. Clinical experiences with autologous osteochondral mosaicplasty in an athletic population: a 17-year prospective multicenter study. Am J Sports Med 2010, 38, 1125-1133.

(12) Kon, E.; Verdonk, P.; Condello, V.; Delcogliano, M.; Dhollander, A.; Filardo, G.; Pignotti, E.; Marcacci, M. Matrix-assisted autologous chondrocyte transplantation for the repair of cartilage defects of the knee: systematic clinical data review and study quality analysis. $\mathrm{Am} \mathrm{J}$ Sports Med 2009, 37 Suppl 1, 156S-166S.

(13) Vasiliadis, H. S.; Wasiak, J. Autologous chondrocyte implantation for full thickness articular cartilage defects of the knee. Cochrane Database Syst Rev 2010, CD003323.

(14) Sundelacruz, S.; Kaplan, D. L. Stem cell- and scaffold-based tissue engineering approaches to osteochondral regenerative medicine. Semin Cell Dev Biol 2009, 20, 646-655.

(15) Langer, R.; Vacanti, J. P. Tissue engineering. Science 1993, 260, 920-926.

(16) Jacobi, M.; Villa, V.; Magnussen, R. A.; Neyret, P. MACI - a new era? Sports Med Arthrosc Rehabil Ther Technol 2011, 3, 10.

(17) Grayson, W. L.; Chao, P. H.; Marolt, D.; Kaplan, D. L.; Vunjak-Novakovic, G. Engineering custom-designed osteochondral tissue grafts. Trends Biotechnol 2008, 26, 181-189.

(18) Nukavarapu, S. P.; Dorcemus, D. L. Osteochondral tissue engineering: current strategies and challenges. Biotechnol Adv 2013, 31, 706-721.

(19) Tampieri, A.; Sprio, S.; Sandri, M.; Valentini, F. Mimicking natural bio-mineralization processes: a new tool for osteochondral scaffold development. Trends Biotechnol 2011, 29, 526535. 
(20) Giannini, S.; Buda, R.; Vannini, F.; Di Caprio, F.; Grigolo, B. Arthroscopic autologous chondrocyte implantation in osteochondral lesions of the talus: Surgical technique and results. Am J Sports Med 2008, 36, 873-880.

(21) Joshi, N.; Reverte-Vinaixa, M.; Diaz-Ferreiro, E. W.; Dominguez-Oronoz, R. Synthetic resorbable scaffolds for the treatment of isolated patellofemoral cartilage defects in young patients: magnetic resonance imaging and clinical evaluation. Am J Sports Med 2012, 40, 12891295.

(22) Kon, E.; Delcogliano, M.; Filardo, G.; Pressato, D.; Busacca, M.; Grigolo, B.; Desando, G.; Marcacci, M. A novel nano-composite multi-layered biomaterial for treatment of osteochondral lesions: technique note and an early stability pilot clinical trial. Injury 2010, 41, 693-701.

(23) Cheng, H. W.; Luk, K. D.; Cheung, K. M.; Chan, B. P. In vitro generation of an osteochondral interface from mesenchymal stem cell-collagen microspheres. Biomaterials 2011, $32,1526-1535$.

(24) Giannini, S.; Buda, R.; Vannini, F.; Cavallo, M.; Grigolo, B. One-step bone marrowderived cell transplantation in talar osteochondral lesions. Clin Orthop Relat Res 2009, 467, 3307-3320.

(25) Jin, C. Z.; Cho, J. H.; Choi, B. H.; Wang, L. M.; Kim, M. S.; Park, S. R.; Yoon, J. H.; Oh, H. J.; Min, B. H. The maturity of tissue-engineered cartilage in vitro affects the repairability for osteochondral defect. Tissue Eng Part A 2011, 17, 3057-3065.

(26) Oliveira, J. M.; Rodrigues, M. T.; Silva, S. S.; Malafaya, P. B.; Gomes, M. E.; Viegas, C. A.; Dias, I. R.; Azevedo, J. T.; Mano, J. F.; Reis, R. L. Novel hydroxyapatite/chitosan bilayered 
scaffold for osteochondral tissue-engineering applications: Scaffold design and its performance when seeded with goat bone marrow stromal cells. Biomaterials 2006, 27, 6123-6137.

(27) Malafaya, P. B.; Pedro, A. J.; Peterbauer, A.; Gabriel, C.; Redl, H.; Reis, R. L. Chitosan particles agglomerated scaffolds for cartilage and osteochondral tissue engineering approaches with adipose tissue derived stem cells. J Mater Sci: Mater Med 2005, 16, 1077-1085.

(28) Guo, X.; Park, H.; Liu, G.; Liu, W.; Cao, Y.; Tabata, Y.; Kasper, F. K.; Mikos, A. G. In vitro generation of an osteochondral construct using injectable hydrogel composites encapsulating rabbit marrow mesenchymal stem cells. Biomaterials 2009, 30, 2741-2752.

(29) Augst, A.; Marolt, D.; Freed, L. E.; Vepari, C.; Meinel, L.; Farley, M.; Fajardo, R.; Patel, N.; Gray, M.; Kaplan, D. L.; Vunjak-Novakovic, G. Effects of chondrogenic and osteogenic regulatory factors on composite constructs grown using human mesenchymal stem cells, silk scaffolds and bioreactors. J R Soc Interface 2008, 5, 929-939.

(30) St-Pierre, J. P.; Gan, L.; Wang, J.; Pilliar, R. M.; Grynpas, M. D.; Kandel, R. A. The incorporation of a zone of calcified cartilage improves the interfacial shear strength between in vitro-formed cartilage and the underlying substrate. Acta Biomater 2012, 8, 1603-1615.

(31) Scotti, C.; Wirz, D.; Wolf, F.; Schaefer, D. J.; Burgin, V.; Daniels, A. U.; Valderrabano, V.; Candrian, C.; Jakob, M.; Martin, I.; Barbero, A. Engineering human cell-based, functionally integrated osteochondral grafts by biological bonding of engineered cartilage tissues to bony scaffolds. Biomaterials 2010, 31, 2252-2259.

(32) Grayson, W. L.; Bhumiratana, S.; Grace Chao, P. H.; Hung, C. T.; Vunjak-Novakovic, G. Spatial regulation of human mesenchymal stem cell differentiation in engineered osteochondral constructs: effects of pre-differentiation, soluble factors and medium perfusion. Osteoarthr Cartilage 2010, 18, 714-723. 
(33) Ho, S. T. B.; Cool, S. M.; Hui, J. H.; Hutmacher, D. W. The influence of fibrin based hydrogels on the chondrogenic differentiation of human bone marrow stromal cells. Biomaterials 2010, 31, 38-47.

(34) Zhou, J.; Xu, C.; Wu, G.; Cao, X.; Zhang, L.; Zhai, Z.; Zheng, Z.; Chen, X.; Wang, Y. In vitro generation of osteochondral differentiation of human marrow mesenchymal stem cells in novel collagen-hydroxyapatite layered scaffolds. Acta Biomater 2011, 7, 3999-4006.

(35) Hung, C. T.; Lima, E. G.; Mauck, R. L.; Takai, E.; LeRoux, M. A.; Lu, H. H.; Stark, R. G.; Guo, X. E.; Ateshian, G. A. Anatomically shaped osteochondral constructs for articular cartilage repair. J Biomech 2003, 36, 1853-1864.

(36) Guo, X.; Liao, J.; Park, H.; Saraf, A.; Raphael, R. M.; Tabata, Y.; Kasper, F. K.; Mikos, A. G. Effects of TGF-beta3 and preculture period of osteogenic cells on the chondrogenic differentiation of rabbit marrow mesenchymal stem cells encapsulated in a bilayered hydrogel composite. Acta Biomater 2010, 6, 2920-2931.

(37) Dormer, N. H.; Singh, M.; Wang, L.; Berkland, C. J.; Detamore, M. S. Osteochondral interface tissue engineering using macroscopic gradients of bioactive signals. Ann Biomed Eng 2010, 38, 2167-2182.

(38) Wang, X.; Wenk, E.; Zhang, X.; Meinel, L.; Vunjak-Novakovic, G.; Kaplan, D. L. Growth factor gradients via microsphere delivery in biopolymer scaffolds for osteochondral tissue engineering. J Control Release 2009, 134, 81-90.

(39) McCanless, J. D.; Jennings, L. K.; Cole, J. A.; Bumgardner, J. D.; Haggard, W. O. In vitro differentiation and biocompatibility of mesenchymal stem cells on a novel platelet releasate-containing injectable composite. J Biomed Mater Res A 2012, 100, 220-229. 
(40) Erisken, C.; Kalyon, D. M.; Wang, H.; Ornek-Ballanco, C.; Xu, J. Osteochondral tissue formation through adipose-derived stromal cell differentiation on biomimetic polycaprolactone nanofibrous scaffolds with graded insulin and Beta-glycerophosphate concentrations. Tissue Eng Pt A 2011, 17, 1239-1252.

(41) Wang, L.; Zhao, L.; Detamore, M. S. Human umbilical cord mesenchymal stromal cells in a sandwich approach for osteochondral tissue engineering. J Tissue Eng Regen Med 2011, 5, $712-721$

(42) Rodrigues, M. T.; Lee, S. J.; Gomes, M. E.; Reis, R. L.; Atala, A.; Yoo, J. J. Bilayered constructs aimed at osteochondral strategies: The influence of medium supplements in the osteogenic and chondrogenic differentiation of amniotic fluid-derived stem cells. Acta Biomater 2012, 8, 2795-2806.

(43) Khanarian, N. T.; Haney, N. M.; Burga, R. A.; Lu, H. H. A functional agarosehydroxyapatite scaffold for osteochondral interface regeneration. Biomaterials 2012, 33, 52475258.

(44) Jiang, J.; Tang, A.; Ateshian, G. A.; Guo, X. E.; Hung, C. T.; Lu, H. H. Bioactive stratified polymer ceramic-hydrogel scaffold for integrative osteochondral repair. Ann Biomed Eng 2010, 38, 2183-2196.

(45) Khanarian, N. T.; Jiang, J.; Wan, L. Q.; Mow, V. C.; Lu, H. H. A hydrogel-mineral composite scaffold for osteochondral interface tissue engineering. Tissue Eng Pt A 2012, 18, $533-545$.

(46) Allan, K. S.; Pilliar, R. M.; Wang, J.; Grynpas, M. D.; Kandel, R. A. Formation of biphasic constructs containing cartilage with a calcified zone interface. Tissue Eng 2007, 13, $167-177$. 
(47) Chen, K.; Teh, T. K. H.; Ravi, S.; Toh, S. L.; Goh, J. C. H. Osteochondral interface generation by rabbit bone marrow stromal cells and osteoblasts coculture. Tissue Eng Pt A 2012, $18,1902-1911$.

(48) Chen, K.; Shi, P.; Teh, T. K. H.; Toh, S. L.; Goh, J. C. In vitro generation of a multilayered osteochondral construct with an osteochondral interface using rabbit bone marrow stromal cells and a silk peptide-based scaffold. J Tissue Eng Regen Med 2013, in press.

(49) Hui, J. H.; Ren, X.; Afizah, M. H.; Chian, K. S.; Mikos, A. G. Oligo[poly(ethylene glycol)fumarate] hydrogel enhances osteochondral repair in porcine femoral condyle defects. Clin Orthop Relat Res 2013, 471, 1174-1185.

(50) Tampieri, A.; Sandri, M.; Landi, E.; Pressato, D.; Francioli, S.; Quarto, R.; Martin, I. Design of graded biomimetic osteochondral composite scaffolds. Biomaterials 2008, 29, 35393546.

(51) Igarashi, T.; Iwasaki, N.; Kasahara, Y.; Minami, A. A cellular implantation system using an injectable ultra-purified alginate gel for repair of osteochondral defects in a rabbit model. $J$ Biomed Mater Res A 2010, 94, 844-855.

(52) Abarrategi, A.; Lopiz-Morales, Y.; Ramos, V.; Civantos, A.; Lopez-Duran, L.; Marco, F.; Lopez-Lacomba, J. L. Chitosan scaffolds for osteochondral tissue regeneration. J Biomed Mater Res $A$ 2010, 95, 1132-1141.

(53) Jansen, E. J. P.; Pieper, J.; Gijbels, M. J. J.; Guldemond, N. A.; Riesle, J.; Van Rhijn, L. W.; Bulstra, S. K.; Kuijer, R. PEOT/PBT based scaffolds with low mechanical properties improve cartilage repair tissue formation in osteochondral defects. J Biomed Mater Res A 2009, $89,444-452$. 
(54) Ikeda, R.; Fujioka, H.; Nagura, I.; Kokubu, T.; Toyokawa, N.; Inui, A.; Makino, T.; Kaneko, H.; Doita, M.; Kurosaka, M. The effect of porosity and mechanical property of a synthetic polymer scaffold on repair of osteochondral defects. Int Orthop 2009, 33, 821-828.

(55) Duan, P.; Pan, Z.; Cao, L.; He, Y.; Wang, H.; Qu, Z.; Dong, J.; Ding, J. The effects of pore size in bilayered poly(lactide-co-glycolide) scaffolds on restoring osteochondral defects in rabbits. J Biomed Mater Res A 2013, 102, 180-192.

(56) D'Onofrio, A.; Cresce, G. D.; Bolgan, I.; Magagna, P.; Piccin, C.; Auriemma, S.; Fabbri, A. Clinical and hemodynamic outcomes after aortic valve replacement with stented and stentless pericardial xenografts: a propensity-matched analysis. J Heart Valve Dis 2011, 20, 319-325.

(57) Ricchetti, E. T.; Aurora, A.; Iannotti, J. P.; Derwin, K. A. Scaffold devices for rotator cuff repair. J Shoulder Elbow Surg 2012, 21, 251-265.

(58) Emans, P. J.; Hulsbosch, M.; Wetzels, G. M.; Bulstra, S. K.; Kuijer, R. Repair of osteochondral defects in rabbits with ectopically produced cartilage. Tissue Eng 2005, 11, 17891796.

(59) Yagihashi, K.; Miyazawa, K.; Togari, K.; Goto, S. Demineralized dentin matrix acts as a scaffold for repair of articular cartilage defects. Calcif Tissue Int 2009, 84, 210-220.

(60) Yang, Q.; Peng, J.; Lu, S. B.; Guo, Q. Y.; Zhao, B.; Zhang, L.; Wang, A. Y.; Xu, W. J.; Xia, Q.; Ma, X. L.; Hu, Y. C.; Xu, B. S. Evaluation of an extracellular matrix-derived acellular biphasic scaffold/cell construct in the repair of a large articular high-load-bearing osteochondral defect in a canine model. Chin Med J (Engl) 2011, 124, 3930-3938.

(61) Yan, L-P.; Silva-Correia J.; Oliveira, M. B.; Vilela, C.; Pereira, H.; Sousa, R. A.; Mano, J. F.; Oliveira, A. L.; Oliveira, J. M.; Reis, R. L. Bilayered silk/silk-NanoCaP scaffolds for 
osteochondral tissue engineering: In vitro and in vivo assessment of biological performance. Acta Biomater 2015, 12, 227-241.

(62) Jiang, C. C.; Chiang, H.; Liao, C. J.; Lin, Y. J.; Kuo, T. F.; Shieh, C. S.; Huang, Y. Y.; Tuan, R. S. Repair of porcine articular cartilage defect with a biphasic osteochondral composite. J Orthop Res 2007, 25, 1277-1290.

(63) Shao, X.; Goh, J. C.; Hutmacher, D. W.; Lee, E. H.; Zigang, G. Repair of large articular osteochondral defects using hybrid scaffolds and bone marrow-derived mesenchymal stem cells in a rabbit model. Tissue Eng 2006, 12, 1539-1551.

(64) Da, H.; Jia, S. J.; Meng, G. L.; Cheng, J. H.; Zhou, W.; Xiong, Z.; Mu, Y. J.; Liu, J. The Impact of Compact Layer in Biphasic Scaffold on Osteochondral Tissue Engineering. PLoS ONE 2013, 8, e 54838.

(65) Liu, L.; Xiong, Z.; Zhang, R.; Jin, L.; Yan, Y. A novel osteochondral scaffold fabricated via multi-nozzle low-temperature deposition manufacturing. J Bioact Compat Pol 2009, 24, 1830.

(66) Huang, X.; Yang, D.; Yan, W.; Shi, Z.; Feng, J.; Gao, Y.; Weng, W.; Yan, S. Osteochondral repair using the combination of fibroblast growth factor and amorphous calcium phosphate/poly(L-lactic acid) hybrid materials. Biomaterials 2007, 28, 3091-3100.

(67) Reyes, R.; Delgado, A.; Sanchez, E.; Fernandez, A.; Hernandez, A.; Evora, C. Repair of an osteochondral defect by sustained delivery of BMP-2 or TGFbetal from a bilayered alginatePLGA scaffold. J Tissue Eng Regen Med 2014, 8, 521-533.

(68) Reyes, R.; Delgado, A.; Solis, R.; Sanchez, E.; Hernandez, A.; San Roman, J.; Evora, C. Cartilage repair by local delivery of TGF-beta1 or BMP-2 from a novel, segmented 
polyurethane/polylactic-co-glycolic bilayered scaffold. J Biomed Mater Res A 2014, 102, 11101120.

(69) Kim, K.; Lam, J.; Lu, S.; Spicer, P. P.; Lueckgen, A.; Tabata, Y.; Wong, M. E.; Jansen, J. A.; Mikos, A. G.; Kasper, F. K. Osteochondral tissue regeneration using a bilayered composite hydrogel with modulating dual growth factor release kinetics in a rabbit model. $J$ Control Release 2013, 168, 166-178.

(70) Dormer, N. H.; Singh, M.; Zhao, L.; Mohan, N.; Berkland, C. J.; Detamore, M. S. Osteochondral interface regeneration of the rabbit knee with macroscopic gradients of bioactive signals. J Biomed Mater Res A 2012, 100, 162-170.

(71) Mohan, N.; Dormer, N. H.; Caldwell, K. L.; Key, V. H.; Berkland, C. J.; Detamore, M. S. Continuous gradients of material composition and growth factors for effective regeneration of the osteochondral interface. Tissue Eng Part A 2011, 17, 2845-2855.

(72) Marmotti, A.; Bruzzone, M.; Bonasia, D. E.; Castoldi, F.; Rossi, R.; Piras, L.; Maiello, A.; Realmuto, C.; Peretti, G. M. One-step osteochondral repair with cartilage fragments in a composite scaffold. Knee Surg Sports Traumatol Arthrosc 2012, 20, 2590-2601.

(73) Xie, X.; Wang, Y.; Zhao, C.; Guo, S.; Liu, S.; Jia, W.; Tuan, R. S.; Zhang, C. Comparative evaluation of MSCs from bone marrow and adipose tissue seeded in PRP-derived scaffold for cartilage regeneration. Biomaterials 2012, 33, 7008-7018.

(74) Sun, Y.; Feng, Y.; Zhang, C. Q.; Chen, S. B.; Cheng, X. G. The regenerative effect of platelet-rich plasma on healing in large osteochondral defects. Int Orthop 2010, 34, 589-597.

(75) Chen, J.; Chen, H.; Li, P.; Diao, H.; Zhu, S.; Dong, L.; Wang, R.; Guo, T.; Zhao, J.; Zhang, J. Simultaneous regeneration of articular cartilage and subchondral bone in vivo using 
MSCs induced by a spatially controlled gene delivery system in bilayered integrated scaffolds. Biomaterials 2011, 32, 4793-4805.

(76) Zhang, W.; Chen, J.; Tao, J.; Hu, C.; Chen, L.; Zhao, H.; Xu, G.; Heng, B. C.; Ouyang, H. W. The promotion of osteochondral repair by combined intra-articular injection of parathyroid hormone-related protein and implantation of a bi-layer collagen-silk scaffold. Biomaterials 2013, 34, 6046-6057.

(77) Chen, H. C.; Chang, Y. H.; Chuang, C. K.; Lin, C. Y.; Sung, L. Y.; Wang, Y. H.; Hu, Y. C. The repair of osteochondral defects using baculovirus-mediated gene transfer with dedifferentiated chondrocytes in bioreactor culture. Biomaterials 2009, 30, 674-681.

(78) Leng, P.; Ding, C. R.; Zhang, H. N.; Wang, Y. Z. Reconstruct large osteochondral defects of the knee with hIGF-1 gene enhanced Mosaicplasty. Knee 2012, 19, 804-811.

(79) Sato, M.; Shin-ya, K.; Lee, J. I.; Ishihara, M.; Nagai, T.; Kaneshiro, N.; Mitani, G.; Tahara, H.; Mochida, J. Human telomerase reverse transcriptase and glucose-regulated protein 78 increase the life span of articular chondrocytes and their repair potential. BMC Musculoskelet Dis 2012, 13, 51.

(80) Sun, J.; Hou, X. K.; Li, X.; Tang, T. T.; Zhang, R. M.; Kuang, Y.; Shi, M. Mosaicplasty associated with gene enhanced tissue engineering for the treatment of acute osteochondral defects in a goat model. Arch Orthop Trauma Surg 2009, 129, 757-771.

(81) Zheng, Y. H.; Su, K.; Jian, Y. T.; Kuang, S. J.; Zhang, Z. G. Basic fibroblast growth factor enhances osteogenic and chondrogenic differentiation of human bone marrow mesenchymal stem cells in coral scaffold constructs. J Tissue Eng Regen Med 2011, 5, 540-550.

(82) Li, B.; Yang, J.; Ma, L.; Li, F.; Tu, Z.; Gao, C. Fabrication of poly(lactide-co-glycolide) scaffold filled with fibrin gel, mesenchymal stem cells, and poly(ethylene oxide)-b-poly(L- 
lysine)/TGF-beta1 plasmid DNA complexes for cartilage restoration in vivo. J Biomed Mater Res A 2013, 101, 3097-3108.

(83) Madry, H.; Kaul, G.; Zurakowski, D.; Vunjak-Novakovic, G.; Cucchiarini, M. Cartilage constructs engineered from chondrocytes overexpressing IGF-I improve the repair of osteochondral defects in a rabbit model. Eur Cells Mater 2012, 25, 229-247.

(84) Ueblacker, P.; Wagner, B.; Vogt, S.; Salzmann, G.; Wexel, G.; Kruger, A.; Plank, C.; Brill, T.; Specht, K.; Hennig, T.; Schillinger, U.; Imhoff, A. B.; Martinek, V.; Gansbacher, B. In vivo analysis of retroviral gene transfer to chondrocytes within collagen scaffolds for the treatment of osteochondral defects. Biomaterials 2007, 28, 4480-4487.

(85) Chang, N. J.; Lin, C. C.; Li, C. F.; Wang, D. A.; Issariyaku, N.; Yeh, M. L. The combined effects of continuous passive motion treatment and acellular PLGA implants on osteochondral regeneration in the rabbit. Biomaterials 2012, 33, 3153-3163.

(86) Chang, N. J.; Lin, C. C.; Li, C. F.; Su, K.; Yeh, M. L. The effect of osteochondral regeneration using polymer constructs and continuous passive motion therapy in the lower weight-bearing zone of femoral trocheal groove in rabbits. Ann Biomed Eng 2013, 41, 385-397.

(87) Pietschmann, M. F.; Horng, A.; Niethammer, T.; Pagenstert, I.; Sievers, B.; Jansson, V.; Glaser, C.; Müller, P. E. Cell quality affects clinical outcome after MACI procedure for cartilage injury of the knee. Knee Surg Sports Traumatol Arthrosc 2009, 17, 1305-1311.

(88) Bedi, A.; Foo, L. F.; Williams Iii, R. J.; Potter, H. G. The maturation of synthetic scaffolds for osteochondral donor sites of the knee: An MRI and T2-mapping analysis. Cartilage 2010, $1,20-28$. 
(89) Giza, E.; Sullivan, M.; Ocel, D.; Lundeen, G.; Mitchell, M. E.; Veris, L.; Walton, J. Matrix-induced autologous chondrocyte implantation of talus articular defects. Foot Ankle Int 2010, 31, 747-753.

(90) Aurich, M.; Bedi, H. S.; Smith, P. J.; Rolauffs, B.; Mückley, T.; Clayton, J.; Blackney, M. Arthroscopic treatment of osteochondral lesions of the ankle with matrix-associated chondrocyte implantation: Early clinical and magnetic resonance imaging results. Am J Sports Med 2011, 39, 311-319.

(91) Barber, F. A.; Dockery, W. D. A computed tomography scan assessment of synthetic multiphase polymer scaffolds used for osteochondral defect repair. Arthroscopy 2011, 27, 60-64. (92) Kon, E.; Delcogliano, M.; Filardo, G.; Busacca, M.; Di Martino, A.; Marcacci, M. Novel nano-composite multilayered biomaterial for osteochondral regeneration: a pilot clinical trial. $\mathrm{Am}$ J Sports Med 2011, 39, 1180-1190.

(93) Macmull, S.; Parratt, M. T.; Bentley, G.; Skinner, J. A.; Carrington, R. W.; Morris, T.; Briggs, T. W. Autologous chondrocyte implantation in the adolescent knee. Am J Sports Med 2011, 39, 1723-1730.

(94) Dhollander, A. A. M.; Liekens, K.; Almqvist, K. F.; Verdonk, R.; Lambrecht, S.; Elewaut, D.; Verbruggen, G.; Verdonk, P. C. M. A pilot study of the use of an osteochondral scaffold plug for cartilage repair in the knee and how to deal with early clinical failures. Arthroscopy 2012, 28, 225-233.

(95) Kon, E.; Vannini, F.; Buda, R.; Filardo, G.; Cavallo, M.; Ruffilli, A.; Nanni, M.; Di Martino, A.; Marcacci, M.; Giannini, S. How to treat osteochondritis dissecans of the knee: Surgical techniques and new trends AAOS exhibit selection. J Bone Joint Surg Am 2012, 94, e1.(1-8) 
(96) Chiang, H.; Liao, C. J.; Hsieh, C. H.; Shen, C. Y.; Huang, Y. Y.; Jiang, C. C. Clinical feasibility of a novel biphasic osteochondral composite for matrix-associated autologous chondrocyte implantation. Osteoarthr Cartilage 2013, 21, 589-598.

(97) Panseri, S.; Russo, A.; Cunha, C.; Bondi, A.; Di Martino, A.; Patella, S.; Kon, E. Osteochondral tissue engineering approaches for articular cartilage and subchondral bone regeneration. Knee Surg Sports Traumatol Arthrosc 2012, 20, 1182-1191.

(98) Nejadnik, H.; Daldrup-Link, H. E. Engineering stem cells for treatment of osteochondral defects. Skeletal Radiol 2012, 41, 1-4.

(99) Nejadnik, H.; Hui, J. H.; Feng Choong, E. P.; Tai, B. C.; Lee, E. H. Autologous bone marrow-derived mesenchymal stem cells versus autologous chondrocyte implantation: an observational cohort study. Am J Sports Med 2010, 38, 1110-1116.

(100) Getgood, A. M.; Kew, S. J.; Brooks, R.; Aberman, H.; Simon, T.; Lynn, A. K.; Rushton, N. Evaluation of early-stage osteochondral defect repair using a biphasic scaffold based on a collagen-glycosaminoglycan biopolymer in a caprine model. Knee 2012, 19, 422-430.

(101) Ding, C.; Qiao, Z.; Jiang, W.; Li, H.; Wei, J.; Zhou, G.; Dai, K. Regeneration of a goat femoral head using a tissue-specific, biphasic scaffold fabricated with CAD/CAM technology. Biomaterials 2013, 34, 6706-6716.

(102) Fedorovich, N. E.; Schuurman, W.; Wijnberg, H. M.; Prins, H. J.; Van Weeren, P. R.; Malda, J.; Alblas, J.; Dhert, W. J. A. Biofabrication of osteochondral tissue equivalents by printing topologically defined, cell-laden hydrogel scaffolds. Tissue Eng Pt C-Meth 2012, 18, 3344. 
(103) Hwang, N. S.; Varghese, S.; Lee, H. J.; Zhang, Z.; Ye, Z.; Bae, J.; Cheng, L.; Elisseeff, J. In vivo commitment and functional tissue regeneration using human embryonic stem cellderived mesenchymal cells. Proc Natl Acad Sci U S A 2008, 105, 20641-20646.

(104) Yamanaka, S. Induced pluripotent stem cells: past, present, and future. Cell Stem Cell 2012, $10,678-684$.

(105) Ko, J. Y.; Kim, K. I.; Park, S.; Im, G. I. In vitro chondrogenesis and in vivo repair of osteochondral defect with human induced pluripotent stem cells. Biomaterials 2014, 35, 35713581. 


\section{For Table of Contents Use Only}

\section{Current Concepts and Challenges in Osteochondral Tissue Engineering and} Regenerative Medicine

Le-Ping Yan, ${ }^{\dagger}$ Joaquim M. Oliveira, ${ }^{* \dagger}$, Ana L. Oliveira, ${ }^{\dagger+}$ Rui L. Reis ${ }^{\dagger+}$
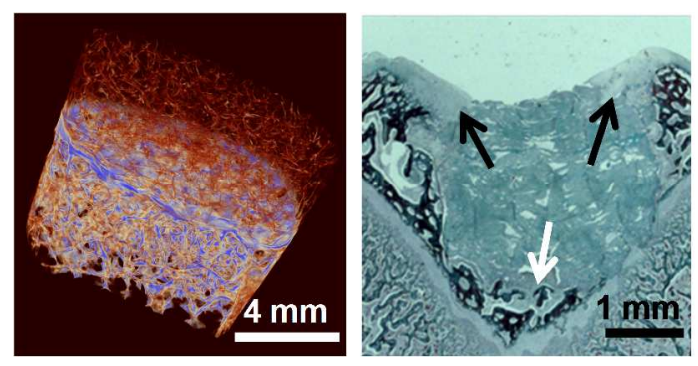

The left is the micro-CT image of bilayered silk/silk-nanoCaP scaffolds recently developed by our group. This image clearly showed the silk matrix (brown) and the CaP phase (blue) distribution in the biphasic and well integrated scaffold. The right is the Masson's trichrome staining image of the osteochondral explant after implantation of the left bilayered scaffold in rabbit OCD for 4 weeks. Black and white arrows indicate neocartilage tissue formed in the top silk layer and subchondral bone grew into the bottom silk-nanoCaP layer. These silk based bilayered scaffolds could be promising candidate for OC regeneration. 